\title{
A Distributed Model of Carbohydrate Transport and Metabolism in the Liver During Rest and High-Intensity Exercise
}

\author{
E Chalhoub \\ Cleveland State University \\ L. Xie \\ Cleveland State University \\ V. Balasubramanian \\ Case Western Reserve University
}

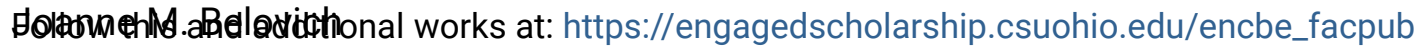

I'veland State University

Part of the Biomechanics and Biotransport Commons

How does access to this work benefit you? Let us know!

\section{Publisher's Statement}

The final publication is available at link.springer.com (http://link.springer.com/article/ 10.1007s10439-006-9217-2)

\section{Original Citation}

Chalhoub, E., Xie, L., Balasubramanian, V., Kim, J., , \& Belovich, J. (2007). A Distributed Model of Carbohydrate Transport and Metabolism in the Liver during Rest and High-Intensity Exercise. Annals of Biomedical Engineering, 35(3), 474 - 491. doi:10.1007/s10439-006-9217-2

\section{Repository Citation}

Chalhoub, E; Xie, L.; Balasubramanian, V.; and Belovich, Joanne M., "A Distributed Model of Carbohydrate Transport and Metabolism in the Liver During Rest and High-Intensity Exercise" (2007). Chemical \& Biomedical Engineering Faculty Publications. 72.

https://engagedscholarship.csuohio.edu/encbe_facpub/72

This Article is brought to you for free and open access by the Chemical \& Biomedical Engineering Department at EngagedScholarship@CSU. It has been accepted for inclusion in Chemical \& Biomedical Engineering Faculty Publications by an authorized administrator of EngagedScholarship@CSU. For more information, please contact library.es@csuohio.edu. 


\title{
A Distributed Model of Carbohydrate Transport and Metabolism in the Liver during Rest and High-Intensity Exercise
}

\author{
E. Chalhoub ${ }^{1}$ L. Xie, ${ }^{1}$ V. Balasubramanian, ${ }^{1}$ J. Kim, ${ }^{2}$ and J. Belovich ${ }^{1}$ \\ ${ }^{1}$ Department of Chemical and Biomedical Engineering, Cleveland State University, 2121 Euclid Avenue, Cleveland, \\ $\mathrm{OH}$ 44115-2425, USA and ${ }^{2}$ Case Western Reserve University, Cleveland, USA
}

\begin{abstract}
A model of reaction and transport in the liver was developed that describes the metabolite concentration and reaction flux dynamics separately within the tissue and blood domains. The blood domain contains equations for convection, axial dispersion, and transport to the surrounding tissue; and the tissue domain consists of reactions representing key carbohydrate metabolic pathways. The model includes the metabolic heterogeneity of the liver by incorporating spatial variation of key enzymatic maximal activities. Simulation results of the overnight fasted, resting state agree closely with experimental values of overall glucose uptake and lactate output by the liver. The incorporation of zonation of glycolytic and gluconeogenic enzyme activities causes the expected increase in glycolysis and decrease in gluconeogenesis along the sinusoid length from periportal to perivenous regions, while fluxes are nearly constant along the sinusoid length in the absence of enzyme zonation. These results confirm that transport limitations are not sufficient to account for the observed tissue heterogeneity of metabolic fluxes. Model results indicate that changes in arterial substrate concentrations and hepatic blood flow rate, which occur in the high-intensity exercise state, are not sufficient to shift the liver metabolism enough to account for the 5-fold increase in hepatic glucose production measured during exercise. Changes in maximal activities, whether caused by exercise-induced changes in insulin, glucagon, or other hormones are shown to be needed to achieve the expected glucose output. This model provides a framework for evaluating the relative importance to hepatic function of various phenomenological changes that occur during exercise. The model can also be used to assess the potential effect of metabolic heterogeneity on metabolism.
\end{abstract}

Keywords-Computer simulation, Modeling, Liver, Carbohydrate metabolism.

\section{INTRODUCTION}

Mathematical models of the liver can be divided into two broad categories: lumped models that consider the organ as well-mixed, and single-drug elimination models that consider the heterogeneous nature of the organ. Garfinkel ${ }^{22}$ developed the first comprehensive model of liver metabolism using the lumped approach and detailed in vitro-based kinetic expressions. Other hepatic carbohydrate metabolism models based on the lumped model approach include that developed by Refai and Bergman (1976), who simulated glycogen metabolism and more recently by Beard and Qian, ${ }^{5}$ who developed a thermodynamic constraint-based model, among others. Numerous others have developed metabolic models that consider specific functions or pathways within the liver, again using the well-mixed approach. Rowland et al. ${ }^{60}$ used this approach to predict the elimination of drugs such as lignocaine and mepridine. In addition to liver models, there is a very large body of work on models of complex metabolic systems (including other organ systems, cell lines, and single-celled organisms) that are based on the well-mixed approach.

While the well-mixed approach may be appropriate for single-celled organisms and cell lines, it is less appropriate for organs, such as the liver, that have a distributed-in-space organization. The human liver is constructed of about 1,000 lobules, with each lobule consisting of about a million channels through which blood flows (the sinusoids), with each sinusoid surrounded by a layer of hepatocytes. The sinusoids are arranged roughly in parallel, and drain into a central vein. Models that consider this distributed-in-space nature have represented the liver by a system of parallel tubes in which blood flows through each tube with the same velocity. The elimination of drugs such as ethanol, galactose, and diazepam has been modeled using this approach (e.g. Saville et al. ${ }^{62}$ ). These models are mathematically simple - they do not include 
dispersion and usually consist of a single species mass balance and single reaction.

Roberts and Rowland proposed a dispersion model of the liver. ${ }^{59}$ As in the parallel tube approach, the dispersion model assumes that the liver is a tubular reactor. In addition, the model includes axial dispersion which is based on cumulative effects of radial variations in velocity, variations in length of the sinusoid, convective mixing in the flow direction of blood in the sinusoid, and diffusion. The model was applied to the drugs antipyrine, carbamazepine, and lignocaine. The model consists of a partial differential equation for the drug in one compartment (sinusoid) and a first order elimination rate

Gray and $\mathrm{Tam}^{27}$ have suggested a model that considers the liver as a series of compartments connected together. The model is based on the tanks-in-series model used by chemical engineers. Each compartment is considered to be well mixed. The model does not differentiate the blood from the tissue compartments. Tsuji et al. ${ }^{68}$ developed a liver model consisting of mass balances for a single species (i.e. drug $\beta$-Lactum antibiotics) in three compartments, representing the sinusoids, space of Disse and tissue.

Bassingthwaite et al. ${ }^{4}$ developed a model for capillary-tissue exchange that combined both the Krogh's cylinder model for the transport of oxygen from the capillary into tissue, and the dispersion model. The model is of a single straight capillary surrounded by a concentric tissue compartment. The model had two sets of equations, one representing concentration in the capillary and the other in the tissue. This model was used to predict the concentration of a metabolite along the axial direction in a capillary, and along axial and radial directions in the tissue. This work was extended to represent parallel multi-capillary systems in King et $a l .{ }^{46}$ and Deussen and Bassingthwaighte. ${ }^{15}$

None of these distributed-in-space models considered the complex network of metabolic pathways found in the liver, nor the unique feature of the liver, that is, the metabolic heterogeneity or zonation shown by the hepatocytes. Hepatocytes from the periportal zone of the liver have different enzyme activities from the perivenous zone. ${ }^{42}$ It has been shown that the periportal zone has relatively high gluconeogenesis rate since the zone is rich in enzyme activities such as glucose-6-phosphatase, fructose 1,6 bisphosphatase and phosphoenolpyruvate carboxykinase, while the perivenous zone is rich in glycolytic enzyme activities such as pyruvate kinase and glucokinase. During the absorptive phase, the perivenous cells take up glucose from the blood and convert it into glycogen and lactate. The lactate is released into the blood stream, and in combination with lactate released by the gut, is then absorbed by the periportal cells and converted to gly- cogen through gluconeogenesis. During the fasting phase, the periportal cells release glucose from the breakdown of glycogen and through gluconeogenesis, while the perivenous cells form lactate through glycogen breakdown.

We have combined the features of the detailed carbohydrate metabolism found in the lumped models with features of the dispersion, Krogh cylinder, and multi-capillary system approaches in order to represent carbohydrate metabolism as well as tissue heterogeneity and axial concentration gradients. The model of the single sinusoid considers two compartments: the blood compartment, with convection, axial dispersion, and transport to the surrounding tissue; and the tissue compartment, where reactions representing key processes of glycolysis, gluconeogenesis, glycogenolysis, tricarboxylic acid cycle, oxidative phosphorylation, and fatty acid degradation and synthesis take place. Each reaction is represented by Michaelis-Menten expressions with modulation by ADP/ATP and/or $\mathrm{NADH} / \mathrm{NAD}^{+}$, as appropriate, using an approach similar to that by Salem et al. ${ }^{61}$. The model includes the metabolic heterogeneity of the liver by incorporating spatial variation of key enzymatic activities. By means of this model one can predict gradients in reaction rates in the tissue, and determine whether these gradients result primarily from concentration gradients in the sinusoid or from zonation of enzyme activities. The results from the single sinusoid model are then scaled-up to provide values for total organ output fluxes and concentrations which are compared to experimental data.

This liver model is intended to be included in a whole-body model being developed by other members of the research team. One of the goals of the wholebody model development is the integration of physiological data related to high-intensity exercise and an improved understanding of controlling factors underlying the physiological response to exercise. To this end, hepatic concentrations and fluxes during the fasted, high-intensity exercise state, were calculated using the model presented here. These simulations allow one to determine the relative importance of various physiological changes that occur during exercise on hepatic glucose/lactate output, such as the increased arterial lactate concentration and the changes in enzymatic activities induced by glucagon secretion.

\section{MODEL DEVELOPMENT}

\section{Overall Liver Model}

The human liver is known to have 1 million lobules, with each lobule containing about 1000 sinusoids. 


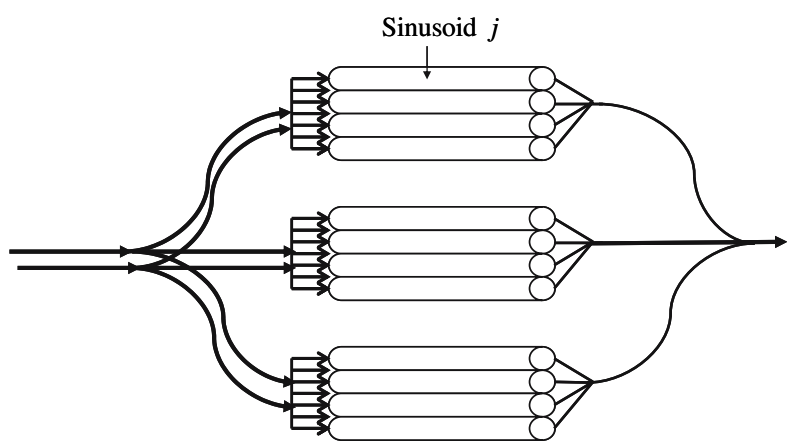

FIGURE 1. Schematic of the lobule structure within the liver.

Each lobule is drained by a central vein, and the output from all lobules is collected in the hepatic vein. Blood flows roughly in parallel through all of the approximately 1 billion sinusoids. A schematic of the liver, which is the basis of the model presented here, is shown in Fig. 1.

The net production rate of species $i$ in sinusoid $j\left(p_{i j}\right)$ is given by a mass balance over the entire sinusoid:

$$
p_{i, j}=\psi_{j} A_{x s, j}\left(\left.C_{i, \text { blood }, j}\right|_{x=L, j}-C_{i, \text { blood }}^{\infty}\right) \leftarrow
$$

where $v_{j}$ is the blood velocity in sinusoid $j, A_{x s, j}$ is the cross-sectional area of each sinusoid calculated from the sinusoid diameter $\left(d_{\mathrm{s}}\right), C^{\infty}$ i,blood is the concentration of species $i$ in the blood upstream of the sinusoid (i.e. mixture of the hepatic artery and portal vein), and
$\left.C_{i, \text { blood }}\right|_{x=L, j}$. is the concentration of species $i$ at the outlet of each sinusoid $j$ (i.e. the central vein). The net production from the entire liver is given by:

$$
P_{i}=\stackrel{n_{\text {sin } u s o i d s}}{\sum_{j}}\left(p_{i, j}\right.
$$

All sinusoids are assumed to have the same length $(L)$, blood velocity $(v)$, and cross-sectional area. The sinusoid length has been reported to be 0.25 $1 \mathrm{~mm} .{ }^{56,51,50}$ Blood velocity distributions have been reported to range from $0-400 \mu \mathrm{m} / \mathrm{s},{ }^{51}$ with means of $69 \mu \mathrm{m} / \mathrm{s}$ in mouse and $180 \mu \mathrm{m} / \mathrm{s}$ in rat, while Koo and Liang ${ }^{47}$ reported velocities of $150-250 \mu \mathrm{m} / \mathrm{s}$ in rat. The sinusoid diameter $\left(d_{\mathrm{s}}\right)$ is reported at values from 4 to $15 \mathrm{um}$, with the diameter slightly increasing from periportal to perivenous ends. ${ }^{50,51,56}$ The actual values used in the model (Table 1) were selected from within the reported ranges, with the criteria that they result in liver geometry that is consistent with macroscopic measurements of human liver. Using the equation for total liver blood flow rate, $Q$, and assuming that all the sinusoids have the same length and velocity (i.e., $v_{j}=v$ ):

$$
Q=\stackrel{n_{\text {sin } u s o i d s}}{\sum_{j}}\left(v_{j} A_{x s, j}\right.
$$

results in $Q=1.47 \mathrm{l} / \mathrm{min}$ blood flow (compared to

\begin{tabular}{|c|c|c|c|}
\hline Variable & Description & Value used in model & Additional information/reference \\
\hline$d_{\mathrm{s}}$ & Diameter of sinusoid & $5.7 \mu \mathrm{m}$ & $\begin{array}{l}4 \mu \mathrm{m}(\mathrm{PP}) \text { and } 5 \mu \mathrm{m}(\mathrm{PP})^{50} ; 5.9 \mu \mathrm{m}(\mathrm{PP}) \text { and } 7.3 \mu \mathrm{m} \\
(\mathrm{PV}) \text { in mice }{ }^{51} ; 7-15 \mu \mathrm{m}^{56} .\end{array}$ \\
\hline$d_{t}$ & $\frac{1}{2}$ of hepatocyte sheet thickness & $5.5 \mu \mathrm{m}$ & $\begin{array}{l}\text { 3.6 } \mu \mathrm{m} \text { (calculated from Goresky et al. }{ }^{26} \text { ) 6-12 um } \\
\text { human hepatocyte radius, } 2.5-8 \text { um in other tissue } \\
\text { (http://www.bartleby.com/107/pages/page1196.html) }\end{array}$ \\
\hline$d_{\mathrm{ed}}$ & $\begin{array}{l}\text { Endothelial cell thickness + } \\
\text { space of Disse }\end{array}$ & $1.8 \mu \mathrm{m}$ & Calculated from Goresky et al. ${ }^{26}$. \\
\hline$L$ & Sinusoid length & $1 \mathrm{~mm}$ & $\begin{array}{l}1 \mathrm{~mm}^{50} ; 0.25 \mathrm{~mm}^{56} ; 0.3 \mathrm{~mm} \text {, estimated } \\
\text { from images }{ }^{51} .\end{array}$ \\
\hline$V_{\text {tissue }}$ & $\begin{array}{l}\text { Volume of tissue surrounding a } \\
\text { single sinusoid }\end{array}$ & $9.5 \times 10^{-8} \mathrm{~cm}^{3}$ & Calculated. \\
\hline$V_{\text {blood }}$ & $\begin{array}{l}\text { Volume of blood within a single } \\
\text { sinusoid plus the space of Disse }\end{array}$ & $4.42 \times 10^{-8} \mathrm{~cm}^{3}$ & Calculated. \\
\hline$v$ & Velocity of blood in sinusoid & $183 \mu \mathrm{m} ;$ yields $\tau=5.4 \mathrm{~s}$ & $\begin{array}{l}\text { Mean values: } 69 \mu \mathrm{m} / \mathrm{s} \text { (mouse) and } 180 \mu \mathrm{m} / \mathrm{s} \\
\text { (rat), range: } 0-400 \mu \mathrm{m} / \mathrm{s}^{51} ; 150,250 \mu \mathrm{m} / \mathrm{s}, \text { rat }^{47}\end{array}$ \\
\hline$n_{\text {sinusoids }}$ & Number of sinusoids in the liver & $5.23 \times 10^{9}$ & \\
\hline$Q$ & Blood flow rate through liver & $1.47 \mathrm{I} / \mathrm{min}$ & \\
\hline$D_{\mathrm{G}}$ & Diffusivity of glucose in blood & $5.46 \times 10^{-4} \mathrm{~cm}^{2} / \mathrm{min}$ & Renkin $^{58}$ \\
\hline$D_{\mathrm{L}}$ & Diffusivity of lactate in blood & $7.71 \times 10^{-4} \mathrm{~cm}^{2} / \mathrm{min}$ & $\begin{array}{l}\text { Calculated using Renkin's model }{ }^{19} . \\
1.013 \times 10^{-4} \times(\mathrm{MW})^{-0.46}\end{array}$ \\
\hline$D_{\mathrm{a}, \mathrm{G}}$ & Dispersion coefficient of glucose & $5.50 \times 10^{-4} \mathrm{~cm}^{2} / \mathrm{min}$ & Calculated using Eq. (4) \\
\hline$D_{\mathrm{a}, \mathrm{L}}$ & Dispersion coefficient of lactate & $7.74 \times 10^{-4} \mathrm{~cm}^{2} / \mathrm{min}$ & Calculated using Eq. (4) \\
\hline
\end{tabular}
$1.51 / \mathrm{min}$ as commonly reported), $83 \%$ liver mass equal

Table 1. Model parameters. 
to hepatocytes (compared to $80 \%$ as commonly reported), and residence time within a single sinusoid of $5 \mathrm{~s}$ (compared to mean residence time of $4 \mathrm{~s}^{24}$ ).

The concentration of each species at the outlet of each sinusoid $\left(C_{i, \text { blood }} \mid x_{x=L, j}\right)$ is obtained from the mass balances comprising the model of the individual sinusoid, given in the following section.

\section{Single Sinusoid Model}

Each sinusoid is lined with endothelial cells, which are separated from the single row of surrounding hepatocytes by the space of Disse (Fig. 2). The endothelial cells contain fenestrae, or pores, that permit dissolved substances in the blood to enter the space of Disse, but prevent transport of large particles such as red blood cells.

An idealized view of the sinusoid is used as the basis for the model (Fig. 3). The liver tissue is represented as a cylindrical region surrounding the sinusoid with a constant cross sectional area. The model can be considered to consist of three domains: the sinusoid, the space of Disse, and the tissue. Goresky et al. ${ }^{26}$ have shown through their tracer studies that species concentrations in the space of Disse equilibrate rapidly and are nearly equal to the species concentrations within the sinusoids. Moreover, convective transport within this region can be considered negligible. Therefore, mass balances are only written for the sinusoid and tissue domains, while the concentrations within the space of Disse are assumed to be equal to the concentrations at the corresponding axial position in the sinusoid.

\section{Governing Equations}

The mass balance for each species in the blood within a single sinusoid is based on the convective flow of blood through the sinusoid, the dispersion occurring due to the flow, and the transport of the metabolite from blood into the hepatocytes. The mass balance equation is given by Taylor's axial dispersion

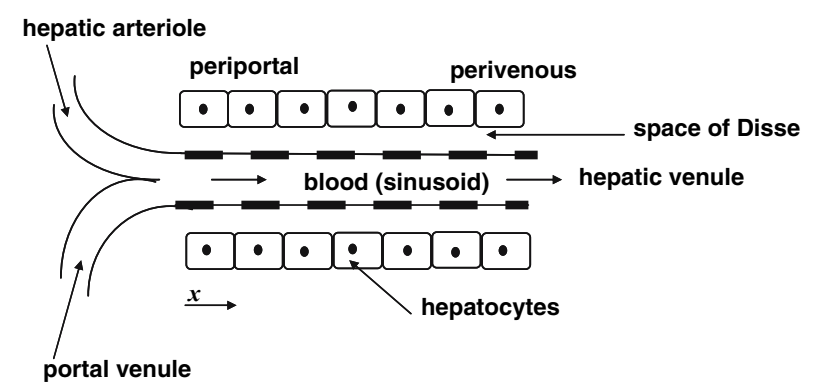

FIGURE 2. Schematic of a single sinusoid.

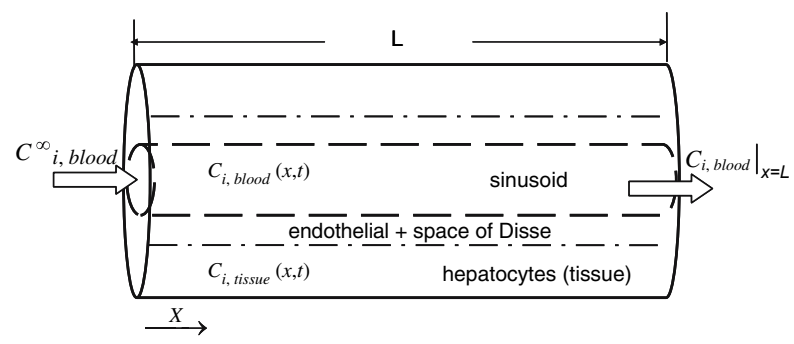

FIGURE 3. Schematic of a single idealized sinusoid as basis for the model. Large arrows represent the flow of blood within the sinusoid. $C_{i, \text { blood }}$ is the concentration of species $i$ within the sinusoid, as function of axial distance and time; $C_{i, \text { tissue }}$ is the concentration of species $i$ within the tissue, as function of axial distance and time; $L$ is the length of an average sinusoid; $C_{i, \text { blood }}^{\infty}$ is the concentration of species $i$ entering the sinusoid from the portal artery and hepatic vein.

model, ${ }^{18}$ which describes the plug flow of a compound through a tubular reactor, with slight modification by including the transport of the species from blood into the tissue:

$$
\frac{\partial C_{i, \text { blood }}}{\partial t}=-v \frac{\partial C_{i, \text { blood }}}{\partial x}+D_{a, i} \frac{\partial^{2} C_{i, \text { blood }}}{\partial x^{2}}-J_{i, b-t}(x, t) \leftarrow
$$

where $C_{i}$ is the concentration of species $i, t$ is time, $x$ is axial distance along the sinusoid, $d_{a, i}$ is the dispersion coefficient, and $J_{i, b-t}$ is the transport flux from the blood into tissue. The kinetics for bi-directional carrier-mediated transport is given by the simplified expression:

$$
J_{i, b-t}=\frac{V_{\text {max }_{i}}\left(C_{i, \text { blood }}-C_{i, \text { tissue }}\right)}{K_{m_{i}}+\left(C_{i, \text { blood }}+C_{i, \text { tissue }}\right)} \leftarrow
$$

The dispersion coefficients were calculated by the ArisTaylor's relation ${ }^{18}$ :

$$
D_{a, i}=D_{i}+\frac{\left(\frac{v d_{\mathrm{s}}}{2}\right)^{2}}{48 D_{i}}
$$

where $d_{i}$ is the diffusion coefficient of species $i$ in blood.

The mass balance of each species in the tissue includes transport between the blood and tissue and reaction kinetics. Due to the relatively small tissue thickness, concentration gradients in the radial direction are neglected. Axial diffusion is also neglected. The tissue here is treated as a set of sub-compartments connected in parallel to the sinusoid domain, via the space of Disse domain. Since the concentrations in the space of Disse equilibrate rapidly with the concentrations in the corresponding position within the sinusoid, the radial flux can be considered to result from the concentration difference between each tissue sub-compartment and the corresponding region of the sinusoid. 
Reactions occur inside each tissue sub-compartment, and each sub-compartment is considered to be wellmixed. The concentration gradient in the tissue is thus driven by different rates of transport into/out of each tissue sub-compartment, as well as different reaction rates in each sub-compartment. The general mass balance equation for each metabolite $i$ in tissue is then:

$$
\frac{\partial C_{i, \text { tissue }}(x, t)}{\partial t} \leftrightarrows J_{i, b-t}^{\prime}(x, t)-R_{i}(x, t)
$$

where $R_{i}=$ rate of reaction of each metabolite within each tissue sub-compartment.

The transport flux for the tissue equation is divided by the volume ratio $\left(V_{\text {ratio }}\right)$ of tissue to blood to make the units consistent for the two compartments. By doing this, the units of the transport flux will be with respect to each compartmental volume:

$$
J_{b-t}^{\leftarrow \leftarrow}=J_{b-t} *\left(\frac{1}{V_{\text {ratio }}}\right) \leftarrow
$$

where $\mathrm{V}_{\text {ratio }}=\mathrm{V}_{\text {tissue }} / \mathrm{V}_{\text {blood }}, V_{\text {tissue }}$ is the volume of tissue surrounding a single sinusoid, and $V_{\text {blood }}$ is the total volume of blood within both a single sinusoid and the space of Disse.

Equations (3) and (5) are made dimensionless in the axial direction by defining the following variables:

$$
\xi=\frac{x}{L} ; \tau=L / v
$$

Using the above variables, Eq. (3) can be written as follows:

$$
\tau \frac{\partial C_{i, \text { blood }}}{\partial t}=-\frac{\partial C_{i, \text { blood }}}{\partial \xi}+\stackrel{1}{P e_{i}} \frac{\partial^{2} C_{i, \text { blood }}}{\partial \xi^{2}}-J_{i, b-t} \tau
$$

where $P e$ is the Peclet number which is defined as

$$
P e_{i}=\frac{v L}{D_{a, i}}
$$

Using the parameter values given in Table $1, P e_{\mathrm{GLC}}$ and $P e_{\text {LAC }}$ are calculated to be 200 and 142, respectively.

The boundary conditions are obtained by assuming that the flow of blood is plug flow (i.e. no dispersion) before entering and after leaving the sinusoids. These are called Danckwert's boundary conditions and represent an open system. The corresponding boundary conditions are given by ${ }^{18}$ :

$$
\begin{array}{cc}
\text { At } x=0:\left.\quad \mathrm{C}_{\mathrm{i}, \text { blood }}\right|_{\mathrm{x}=0}=\mathrm{C}_{\mathrm{i}, \text { blood }}^{\infty}+\frac{\mathrm{D}_{\mathrm{a}, \mathrm{i}}}{\mathrm{v}} \frac{\partial \mathrm{C}_{\mathrm{i}}}{\partial \mathrm{x}} & (8) \leftarrow \\
\text { At } x=L: \quad \frac{\partial C_{i, \text { blood }}}{\partial x}=0 & (9) \leftarrow
\end{array}
$$

The initial conditions depend upon the physiological state and will be discussed in the results section.

\section{Metabolic Pathway}

Simplified pathways representing glycolysis, gluconeogenesis, glycogenolysis, glycogen synthesis, citric acid cycle, oxidative phosphorylation, triglyceride breakdown, and fatty acid synthesis and degradation were included (Fig. 4). Each of these pathways is represented by 1-4 key reactions. The name of the reaction either corresponds to the enzyme name (when representing a single reaction) or to the names of the substrate and product (when representing a series of reactions lumped together). Kinetic expressions are given in Table 2. Reversible, near-equilibrium reactions $\left(\mathrm{R}_{\mathrm{GAP} \rightarrow \mathrm{PEP}}, \mathrm{R}_{\mathrm{LAC} \rightarrow \mathrm{PYR}}\right)$ are represented by a simplified form of a reversible, ping-pong mechanism. All other reactions are assumed to be essentially irreversible and are represented by Michaelis-Menten kinetic expressions with modulation by $C_{\mathrm{ADP}} / C_{\mathrm{ATP}}$ and $C_{\mathrm{NADH}} / C_{\mathrm{NAD}}+$ as relevant. The flux through the citric acid cycle was assumed to exist in an additive "ping-pong" relationship. ${ }^{61}$

Kinetic parameters were estimated from concentration and flux data measured at the overnight fasted, resting state. The input and output fluxes at steady state were estimated from a combination of in vivo experiments on humans and dogs and internal fluxes were then calculated using flux balance analysis (FBA). Species concentrations were compiled mostly from experiments with overnight fasted rats. The set of experimental and calculated fluxes and concentrations are shown in Tables 2 and 3. In the case of irreversible reactions, the $K_{\mathrm{m}}$ in each reaction was set equal to the experimental substrate concentration at steady state, the $K_{\mathrm{m}}$ for $C_{\mathrm{ADP}} / C_{\mathrm{ATP}}$, represented by $P S_{i}$, was set equal to the steady state experimental $C_{\mathrm{ADP}} / C_{\mathrm{ATP}}$ ratio, and the $K_{\mathrm{m}}$ for $C_{\mathrm{NADH}} / C_{\mathrm{NAD}+}$, represented by $R S_{i}$, was set equal to the experimental $C_{\mathrm{NADH}} / C_{\mathrm{NAD}+}$ ratio, all measured in animals following an overnight fast. From these parameter values and concentration and flux values, the $V_{\max }$ 's were calculated uniquely using the kinetic expressions. Reversible reactions were handled differently. In general, the $V_{\max }$ 's and $K_{\text {eq }}$ 's were determined from in vitro measurements, and then the $\mathrm{K}_{\mathrm{m}}$ 's were calculated such that the net flux through the reaction matched the experimental (or FBAcalculated) flux. The Haldane equation (relating kinetic parameter values at near-equilibrium) was used to reduce the number of unknown parameters and to ensure consistency with thermodynamic constraints. If no kinetic expression is given, then that flux was 


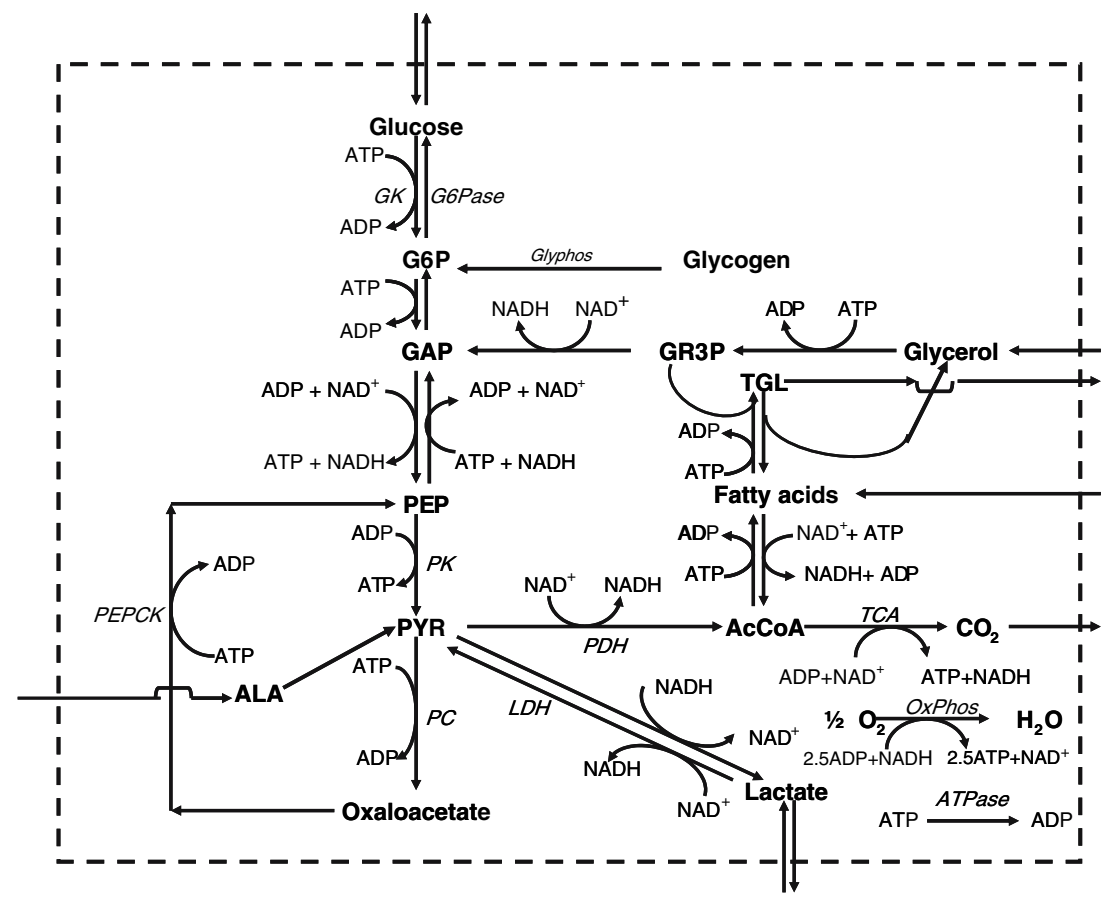

FIGURE 4. Reaction network considered in tissue model. Arrows without enzyme names indicate a series of reactions that have been lumped together. The ATPase reaction represents the total of all ATP-utilizing reactions that are not considered explicitly in the model. GK: glucokinase; G6Pase: glucose-6-phosphatase; Glyphos: glycogen phosphorylase; OxPhos: oxidative phosphorylation, PK: pyruvate kinase; PC: pyruvate carboxylase; PEPCK: phosphoenylpyruvate carboxykinase; PDH: pyruvate dehydrogenase; LDH: lactate dehydrogenase; G6P: glucose-6-phosphate; GAP: glyceraldehyde-3-phosphate; GR3P: glycerol-3-phosphate; PEP: phosphoenylpyruvate; AcCoA: acetyl CoA.

assigned a constant value in the model, given by either the measured or calculated flux.

The zonation phenomenon is incorporated into the model by assuming either linear $\left(V_{\max }=V_{\mathrm{o}, 1}+a \cdot x /\right.$ $L)$ or exponential $\left(V_{\max }=V_{\mathrm{o}, \mathrm{e}} \cdot \exp (b \cdot x / L)\right.$ variations in maximal activities for the reactions for which the phenomenon has been observed. The parameter values in these functions were determined by assuming that the relative changes in maximal enzyme activities between the periportal and perivenous regions are similar to those reported in the literature (Table 3), and that the maximal activities at $x / L=0.5$ are given by the values in Table 2. The parameters used in the functions for $V_{\max }$ are given in Table 3 and the functions are graphed in Fig. 5 (Table 4). The use of exponential functions is based on the hypothesis that substrate concentration gradients along the sinusoid are most likely exponential (e.g. as measured for $\mathrm{pO}_{2}$ ), which may influence the distribution of enzyme activity. There is clear literature support for the zonation of glucokinase (GK), glucose-6-phosphatase (G6Pase), fructose-1,6-bis-phosphatase (represented

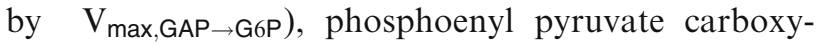
kinase (PEPCK), and pyruvate kinase (PK). Although zonation of pyruvate carboxylase (PC) has not been specifically reported, because of this enzyme's key role in gluconeogenesis, the zonation of $V_{\text {max,PC }}$ was included using a function similar to that

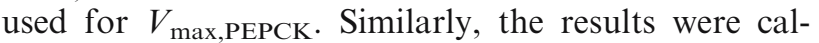
culated with zonation of phosphofructokinase (represented by $\left.V_{\max , G 6 P \rightarrow G A P}\right)$ using a similar function to that of GK. The incorporation of zonation of $V_{\text {max, G6P } \rightarrow \text { GAP }}$ did not change any of the flux profiles, except for that of $\mathrm{V}_{\mathrm{G} G \mathrm{P} \rightarrow \mathrm{GAP}}$ itself (data not shown), and thus does not seem to be essential. Although zonation is also known to occur in lipid metabolism, this was not addressed in this work since detailed lipid metabolism kinetics are not included in the model.

The model consists of 13 mass balances: glucose in blood and tissue $\left(\mathrm{GLC}_{\mathrm{b}}, \mathrm{GLC}_{\mathrm{t}}\right)$, lactate in blood and tissue $\left(\mathrm{LAC}_{\mathrm{b}}, \mathrm{LAC}_{\mathrm{t}}\right)$, and in tissue only: glucose-6phosphate (G6P), phosphoenolpyruvate (PEP), pyruvate (PYR), AcCoA, oxaloacetate (OXA), ATP, NADH, glycogen (GLY), glyceraldehyde-3-phosphate (GAP). The quantities $C_{\mathrm{NADH}}+C_{\mathrm{NAD}+}, C_{\mathrm{ATP}}+-$ $C_{\mathrm{ADP}}$, and $C_{\mathrm{Pi}}$ are assumed to be constant, with values given in Table 3 .

The governing equations in the blood, which is a partial differential equation for each species in the blood, were converted to ordinary differential equations by means of the finite difference method using 
Table 2. Fluxes, kinetic expressions and parameter values. ( $\left.\mathrm{PS}=\mathrm{C}_{\mathrm{ATP}} / \mathrm{C}_{\mathrm{ADP}} ; \mathrm{RS}=\mathrm{C}_{\mathrm{NAD}+} / \mathrm{C}_{\mathrm{NADH}}\right)$

\begin{tabular}{|c|c|c|c|c|}
\hline Rate & $\begin{array}{l}\text { Flux used for parameter } \\
\text { estimation ( } \mu \text { mol substrate } \\
\text { /gww.hep/min, unless } \\
\text { otherwise specified), derived } \\
\text { from either experimental } \\
\text { data (with reference given), } \\
\text { or calculated from flux } \\
\text { balance analysis }\end{array}$ & $\begin{array}{l}\text { Flux calculated } \\
\text { from simulation } \\
\text { ( } \mu \text { mol substrate/ } \\
\text { gww hep/min) }\end{array}$ & Kinetic expression & $\begin{array}{l}\text { Parameter values } \\
\left(V_{\max } \text { in } \mu \mathrm{mol} / \mathrm{gww} / \mathrm{min} ;\right. \\
\left.K_{\mathrm{m}} \text { in } \mu \mathrm{mol} / \mathrm{gww}\right) \\
\end{array}$ \\
\hline$R_{\mathrm{GK}}$ & 0.136 (Shulman, et al. ${ }^{64}$ ) & 0.14 & $\frac{\mathrm{V}_{\max , G K} \mathrm{C}_{\mathrm{GLC} \_t}}{\mathrm{~K}_{\mathrm{m}, \mathrm{GK}}+\mathrm{C}_{\mathrm{GLC} \_t}}\left(\left(\frac{1 / \mathrm{PS}}{\left(\mathrm{PS} \mathrm{S}_{\mathrm{i}}+1 / \mathrm{PS}\right.}\right)(\right.$ & $\begin{array}{l}V_{\max , \mathrm{GK}}=0.54 \\
K_{\mathrm{M}, \mathrm{GK}}=3.61 \\
\mathrm{PS}_{\mathrm{i}}=0.45\end{array}$ \\
\hline$R_{\mathrm{G} 6 \mathrm{Pase}}$ & $0.721^{*}$ & 0.717 & $\frac{V_{\text {max.GGase }} C_{G G P}}{K_{m, G 6 \text { Pase }}+C_{G G P}}$ & $\begin{array}{l}V_{\text {max,G6Pase }}=1.41 \\
K_{\mathrm{m}, \mathrm{G} 6 \text { Pase }}=0.06\end{array}$ \\
\hline$R_{\text {GlyPhos }}$ & $0.304 \mu$ mole $\mathrm{C} 6 / \mathrm{gww} / \mathrm{min}^{55}$ & & & \\
\hline $\mathrm{R}_{\mathrm{G} G \mathrm{P} \rightarrow \mathrm{GAP}}$ & $\begin{array}{l}0.136 \mu \text { mole } \mathrm{C} 6 / \mathrm{gww} / \mathrm{min} \\
\text { (Shulman et al. }{ }^{64} \text { ) }\end{array}$ & 0.134 & 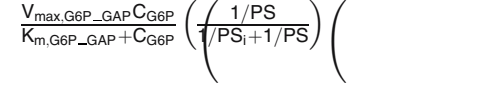 & $\begin{array}{l}V_{\text {max }, G 6 P \_G A P}=0.54 \\
K_{m} \text {. }\end{array}$ \\
\hline $\mathrm{R}_{\mathrm{GAP}->\mathrm{G} 6 \mathrm{P}}$ & $0.83 \mu \mathrm{mole}$ C3/gww/min* & 0.815 & 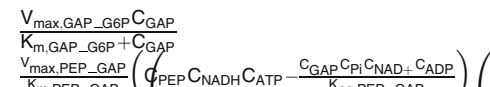 & $\begin{array}{l}n_{\mathrm{m}, \mathrm{G} 6 P} \text { _GAP } \\
V_{\text {max,GAP_G6P }}=1.60 \\
K_{\mathrm{m}, \mathrm{GAP} \text { G6P }}=0.0031\end{array}$ \\
\hline $\mathrm{R}_{\mathrm{PEP}->\mathrm{GAP}, \text { net }}$ & $0.472^{*}$ & 0.458 & 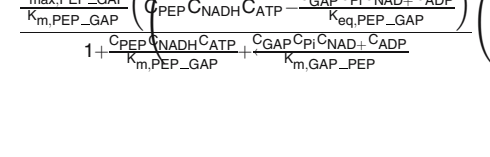 & $\begin{array}{l}\left.V_{\text {max,PEP_GAP }}=94^{16}\right) \\
K_{\text {m,PEP_GAP }}=2.7 \times 10^{-4} \\
K_{\text {m,GAP_PEP }}=1.75 \times 10^{-4} \\
\left.K_{\text {eq,PEP_GAP }}=4167^{57}\right)\end{array}$ \\
\hline $\mathrm{R}_{\mathrm{GR} 3 \mathrm{P}->\mathrm{GAP}}$ & $\begin{array}{l}0.0888^{*} \text {; } \\
\left(0.112 \text { in Brundin et al. }{ }^{13}\right)\end{array}$ & & & \\
\hline$R_{\mathrm{PK}}$ & $0.94^{*}$ & 0.931 & 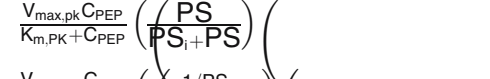 & $\begin{array}{l}V_{\max , \mathrm{PK}}=3.78 \\
K_{\mathrm{m}, \mathrm{PK}}=0.046\end{array}$ \\
\hline$R_{\mathrm{PC}}$ & $1.416^{\star}$ & 1.39 & $\frac{V_{\text {max }, P C} C_{P Y R}}{K_{m, P C}+C_{P Y R}}\left(\frac{1 / P S}{\left(/ P S_{i}+1 / P S\right.}\right)^{\prime}($ & $\begin{array}{l}V_{\max , \mathrm{PC}}=5.66 \\
K_{\mathrm{m}, \mathrm{PC}}=0.059\end{array}$ \\
\hline$R_{\text {PEPCK }}$ & $1.416^{44}$ & 1.39 & $\frac{\mathrm{V}_{\text {max }, \text { PEPCK }} \mathrm{C}_{\mathrm{OXA}}}{\mathrm{K}_{\mathrm{m}, \mathrm{PEPCK}}+\mathrm{C}_{\mathrm{OXA}}}\left(\frac{1 / \mathrm{PS}}{\sqrt{\mathrm{PS}}+1 / \mathrm{PS}}\right)($ & $\begin{array}{l}V_{\text {max }, \text { PEPCK }}=5.66 \\
K_{\mathrm{m}, \mathrm{PEPCK}}=0.0003\end{array}$ \\
\hline$R_{\mathrm{PDH}}$ & $0.0^{52}$ & & $\frac{v_{\text {max,LLH }}}{K_{\text {mLACPYR }}}\left(\oint_{L A C C_{\text {NAD }+}-}-\frac{C_{P Y R} C_{\text {NADH }}}{K_{\text {KeqLLD }}}\right)^{\prime}$ & \\
\hline $\mathrm{R}_{\mathrm{LAC}->\mathrm{PYR} \text {,net }}$ & $0.216^{*}$ & 0.201 & 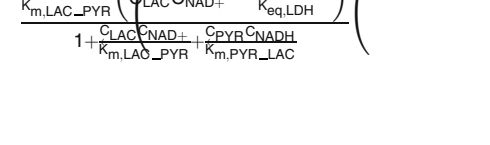 & $\begin{array}{l}V_{\max , \text { LDH }}=195^{16} \\
K_{\mathrm{m}, \mathrm{LAC} \_P Y R}=1.19 \\
K_{\mathrm{m}, \mathrm{PYR} \_ \text {LAC }}=2.29 \times 10^{-7} \\
K_{\text {eq,LDH }}=1.64 \times 10^{-4}{ }^{\star *}\end{array}$ \\
\hline$R_{\mathrm{TCA}}-$ & $0.78 \mu \mathrm{mole}$ C2/gww/min* & 0.78 & $\begin{array}{l}\mathrm{V}_{\mathrm{mzX}, \mathrm{TCA}}[\mathrm{AcCoA}] \leftarrow \\
\times\left(\varepsilon \frac{1 / \mathrm{RS}}{1 / \mathrm{RS}_{\mathrm{i}+1 / \mathrm{RS}}}+(1-\varepsilon) \frac{1 / \mathrm{PS}}{1 / \mathrm{PS}_{\mathrm{i}}+1 / \mathrm{PS}}\right)\end{array}$ & $\begin{array}{l}V_{\max , \mathrm{TCA}}=15.62 \\
\varepsilon=0.75^{61}\end{array}$ \\
\hline$R_{\text {OxPhos }}$ & $2.11 \mu \mathrm{mole}^{\star} \mathrm{O}_{2} / \mathrm{gww} / \mathrm{min}^{12}$ ) & 2.11 & $\frac{V_{\text {max }} \text { QxPhos }}{\mathrm{K}_{\mathrm{m}, \mathrm{OxPhos}}+\mathrm{C}_{\mathrm{O}_{2}}}\left(\frac{\mathrm{PS}}{\mathrm{PS}+\mathrm{PS} \mathrm{S}_{\mathrm{i}}}\right)\left(\frac{(\mathrm{RS}}{\mathrm{pS}}\right)($ & $\begin{array}{l}V_{\max , \text { OxPhos }}=16.9 \\
K_{\mathrm{m}} \text {, xPhos } \\
=7.33\end{array}$ \\
\hline$J_{\mathrm{Glc}, \mathrm{b} \_\mathrm{t} \_n e t}$ & $-0.585^{13,9}$ & -0.577 & 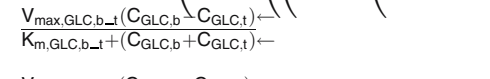 & $\begin{array}{l}V_{\max , \mathrm{GLC}, \mathrm{b} \_\mathrm{t}}=57.0 \\
K_{\mathrm{m}, \mathrm{GLC}, \mathrm{b} \_\mathrm{t}}=3.61\end{array}$ \\
\hline$J_{\text {LAC,b_t_net }}$ & $0.216^{69}$ & 0.202 & $\frac{V_{\text {max } L A C, b\lrcorner t}\left(C_{L A C, b}-C_{L A C, t}\right) \leftarrow}{K_{m, L A C, b \_t}+\left(C_{L A C, b}+C_{L A C, t}\right) \leftarrow}$ & $\begin{array}{l}V_{\max , \mathrm{LAC}, \mathrm{b} \_\mathrm{t}}=3.24 \\
K_{\mathrm{m}, \mathrm{LAC}, \mathrm{b} \_\mathrm{t}}=1.2\end{array}$ \\
\hline $\mathrm{R}_{\mathrm{FA}->\mathrm{AcCoA}}$ & $0.87 \mu$ mole $\mathrm{C} 2 / \mathrm{gww} / \mathrm{min}^{*}$ & & & \\
\hline $\mathrm{R}_{\mathrm{FA}, \text { blood->FA,tissue }}$ & $1.345 \mu \mathrm{mole} \dagger \mathrm{C} 2 / \mathrm{gww} / \mathrm{min}$ & & & \\
\hline $\mathrm{R}_{\mathrm{AcCoA}->\mathrm{FA}}$ & $0.09 \mu$ mole C2/gww/min * & & & \\
\hline $\mathrm{R}_{\mathrm{GLR}->\mathrm{GR} 3 \mathrm{P}}$ & $0.1152^{*}$ & & & \\
\hline $\mathrm{R}_{\mathrm{GR} 3 \mathrm{P}+3 \mathrm{FA}->\mathrm{TG}}$ & $0.0264 \mu \mathrm{mole} T \mathrm{TG} / \mathrm{gww} / \mathrm{min}$ * & & & \\
\hline $\mathrm{R}_{\mathrm{TG}->\mathrm{GLR}+3 \mathrm{FA}}$ & $0.0032 \mu \mathrm{mole} T \mathrm{TG} / \mathrm{gww} / \mathrm{min}$ * & & & \\
\hline $\mathrm{R}_{\mathrm{TG}, \text { tissue->TG,blood }}$ & $\begin{array}{l}0.023 \mu \text { mole TG/gww/min } \\
\left(0.065 \text { in Jensen }{ }^{36}\right) \ddagger \leftarrow\end{array}$ & & & \\
\hline $\mathrm{R}_{\mathrm{GLR}, \text { blood }->\mathrm{GLR} \text {,tissue }}$ & $0.112^{37}$ & & & \\
\hline $\mathrm{R}_{\mathrm{ATP}->\mathrm{ADP}}$ & $8.73^{*}$ & 8.29 & 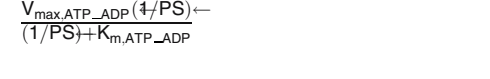 & $\begin{array}{l}V_{\max \_A T P \perp A D P}=16.71 \\
K_{\mathrm{m} \backslash A T P \backslash \_A D P}=2.25\end{array}$ \\
\hline$R_{A L A->P Y R}$ & $0.256^{65}$ & & & \\
\hline
\end{tabular}

*Value calculated via Flux Balance Analysis (FBA).

$\ddagger$ Some of the input/output fluxes used deviate somewhat from experimental reports. Since this model is to be used in a model of the whole body, the input and output fluxes were required to be consistent with the overall balances in the body for species such of FA, TGL, Glc, ALA, GLR, and LAC. GLR: glycerol; Glc: glucose; Gly: glycogen; LAC: lactate; OXA: oxaloacetate.

${ }^{* *}$ Value calculated based on the Gibbs function data from Alberty, $2003^{1}$ 
Table 3 Species concentrations in liver tissue, at the overnight fasted state, used to estimate kinetic parameters. Units are $\mu \mathrm{mol}_{\text {gww }}{ }^{-1}$ hep.

\begin{tabular}{|c|c|c|}
\hline Species & $\begin{array}{l}\text { Concentration used } \\
\text { to estimate parameters }\end{array}$ & Reference \\
\hline Glc,tissue & 3.61 & Bergmeyer $^{8}$ \\
\hline Glc,blood & 3.5 & Bergman et al. $^{7}$ \\
\hline G6P & 0.06 & Bergmeyer $^{8}$ \\
\hline glycogen & 391 & Petersen et al. ${ }^{55}$ \\
\hline GAP & 0.0031 & Stubs et al. ${ }^{67}$ \\
\hline GR3P & 0.281 & Bergmeyer $^{8}$ \\
\hline PEP & .046 & Bergmeyer $^{8}$ \\
\hline PYR & 0.059 & Stubbs et al. ${ }^{67}$ \\
\hline OXA & 0.0003 & Bergmeyer $^{8}$ \\
\hline LAC,blood & 1.2 & Bergmeyer $^{8}$ \\
\hline LAC,tissue & 0.98 & Krebs $^{48}$ \\
\hline AcCoA & 0.1 & Bergmeyer $^{8}$ \\
\hline Oxygen & 7.33 & Brundin et al. ${ }^{12}$ \\
\hline ATP & 3.43 & $\begin{array}{l}\text { Gyorgy et al. }{ }^{30} ; \\
\text { Morikawa et al. } \\
\text { Gannon et al. } \\
\text { Hultman et al. } \\
\text { Boesiger et al. }\end{array}$ \\
\hline \multicolumn{3}{|l|}{ ATP+ADP } \\
\hline $\mathrm{NADH}+\mathrm{NAD}^{+}$ & 1.22 & Bergmeyer $^{8}$ \\
\hline $\mathrm{NADH} / \mathrm{NAD}^{+}$ & .0014 & Stubbs ${ }^{67}$ \\
\hline $\mathrm{Pi}$ & 5.74 & $\begin{array}{l}\text { Morikawa et al. }{ }^{54} \text {; } \\
\text { Bode et al. }{ }^{10}\end{array}$ \\
\hline
\end{tabular}

200 grid points. The governing equations in the tissue were written for each species for each of the 200 grid points. All ODE's were then solved simultaneously using the FORTRAN routine LSODE.

The sensitivities of concentration of species $i\left(C_{i}\right)$ and flux $i\left(R_{i}\right)$ to parameter $K_{j}$ are defined as:

$$
S_{C_{i, j}}=\frac{\partial C_{i} / C_{i}}{\partial K_{j} / K_{j}} ; \quad S_{R_{i, j}}=\frac{\partial R_{i} / R_{i}}{\partial K_{j} / K_{j}}
$$

Partial derivatives were estimated by central finite differences.

\section{RESULTS}

Simulations were first performed at the resting, overnight fasted state, without zonation, and with boundary conditions given by:

$$
\begin{aligned}
& C_{\mathrm{GLC}, \text { blood }}^{\infty}=\{3.5 \mathrm{mM} \\
& C_{\mathrm{LAC}, \text { blood }}^{\infty}=4.2 \mathrm{mM}
\end{aligned}
$$

The resulting fluxes are nearly identical to the experimental (Table 2) and the calculated concentrations agree closely with the experimental concentrations
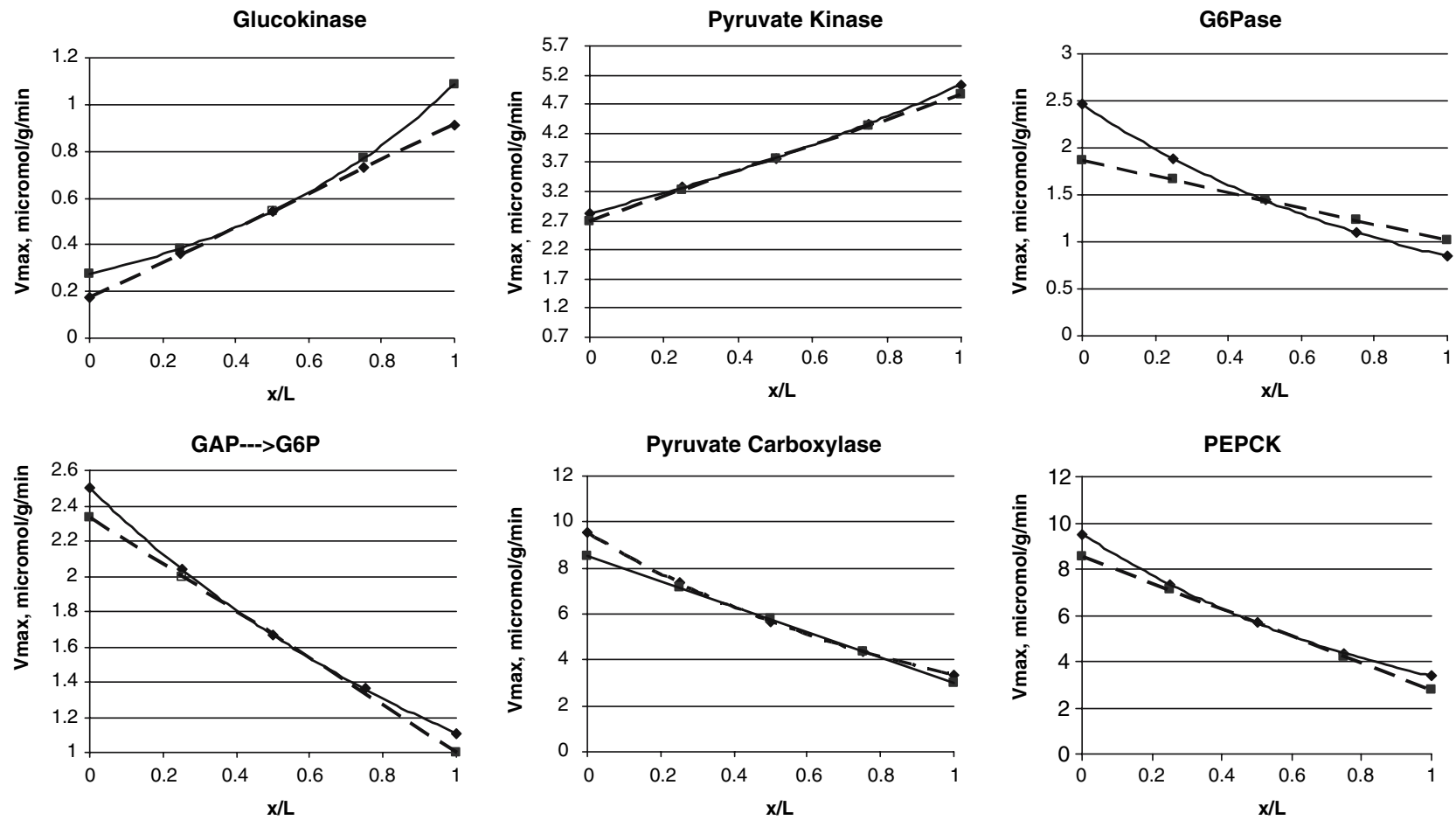

FIGURE 5. Linear and exponential functions of $V_{\max }$ as a function of distance along the sinusoid length. Functions are fitted by assuming that the $V_{\max }$ (given in Table 2) occurs at $x / L=0.5$, and using the ratio of maximal activities from periportal to perivenous, derived from data found in the references in Table 4 . Function parameters are given in Table 4 . The dashed line is a linear fit to the data, solid line is exponential fit. 
Table 4. Literature sources for maximal enzyme activities in periportal and perivenous regions, and the parameters values used in the linear $\left(V_{\max }=V_{0,1}+a \cdot x / L\right)$ or exponential $\left(V_{\max }=V_{0, e} \exp (b \cdot x / L)\right.$ zonation functions.

\begin{tabular}{|c|c|c|c|c|c|}
\hline Reaction & Reference & $V_{o, 1}(\mu \mathrm{mol} / \mathrm{g} / \mathrm{min})$ & $a(\mu \mathrm{mol} / \mathrm{g} / \mathrm{min})$ & $V_{o, e}(\mu \mathrm{mol} / \mathrm{g} / \mathrm{min})$ & $b(\mu \mathrm{mol} / \mathrm{g} / \mathrm{min})$ \\
\hline$V_{\max , \mathrm{GK}}$ & Jungermann et al. ${ }^{42}$ & 0.17 & 0.74 & 0.27 & 1.39 \\
\hline$V_{\max , \mathrm{G} 6 \mathrm{Pase}}$ & Katz et al. ${ }^{45}$ & 1.87 & -0.87 & 2.46 & -1.07 \\
\hline $\mathrm{V}_{\max , \mathrm{GAP} \rightarrow \mathrm{G} 6 \mathrm{P}}$ & Matsumura et al. ${ }^{53}$ & 2.70 & 2.16 & 2.83 & 0.58 \\
\hline$V_{\max , \mathrm{PK}}$ & Guder and Schmidt ${ }^{29} ;$ Jungermann ${ }^{40}$ & 2.33 & -1.33 & 2.50 & -0.81 \\
\hline$V_{\text {max,PEPCK }}$ & Guder and Schmidt ${ }^{29}$; Matsumura et al. ${ }^{53}$ & 8.54 & -5.76 & 9.52 & -1.04 \\
\hline$V_{\max , \mathrm{PC}}$ & & 8.54 & -5.76 & 9.52 & -1.04 \\
\hline
\end{tabular}

(not shown). Since these fluxes and concentrations were used to estimate the kinetic parameters, these results indicate that the program and model are consistent and do not constitute independent verification of the model.

The total glucose output and lactate uptake by the liver in the fasted, resting state, calculated from Eq. (2) and assuming constant $V_{\max }$ 's, are shown in Fig. 6. The simulated values for both glucose output and lactate uptake are nearly identical to experimental values. The incorporation of zonation, whether linear or exponential, has no effect on the overall liver output, mainly because the functions used in zonation were based on setting the $V_{\max }$ (at $x / L=0.5$ ) equal to the constant $V_{\max }$ used in the "no zonation" simulation.

The net glucose production and lactate uptake rates along the sinusoid length are shown in Fig. 7. As shown in Fig. 7a (with no zonation), the net glucose and lactate fluxes are essentially constant along the length of the sinusoid, indicating that at the relatively high blood velocities (and therefore $P e$ ), the species concentration gradients in the axial direction are minimal, causing little variations in fluxes. Figures $7(b-g)$ show the results from simulations where a single enzyme has its $V_{\max }$ as a function of distance. These results indicate that PK, F1,6BPase (represented by GAP $\rightarrow$ G6P), and PC have the greatest influence on spatial variation in glucose and lactate fluxes. With zonation of all six reactions (Fig. 7h), synergistic effects are observed with a $35 \%$ decrease in glucose production between periportal and perivenous regions, and with lactate flux changing from uptake (in periportal) to production in the perivenous region. Experimental values ${ }^{36}$ of net glucose production from microdissected liver tissue and from cultured hepatocytes stimulated to represent either periportal or perivenous cells are shown in Fig. 7h. While the magnitude of change between periportal and perivenous was greater in the experiments than the simulations, the simulations do show the expected trend. Furthermore, there is significant uncertainty in the experimental data. For instance, the data from the liver tissue are
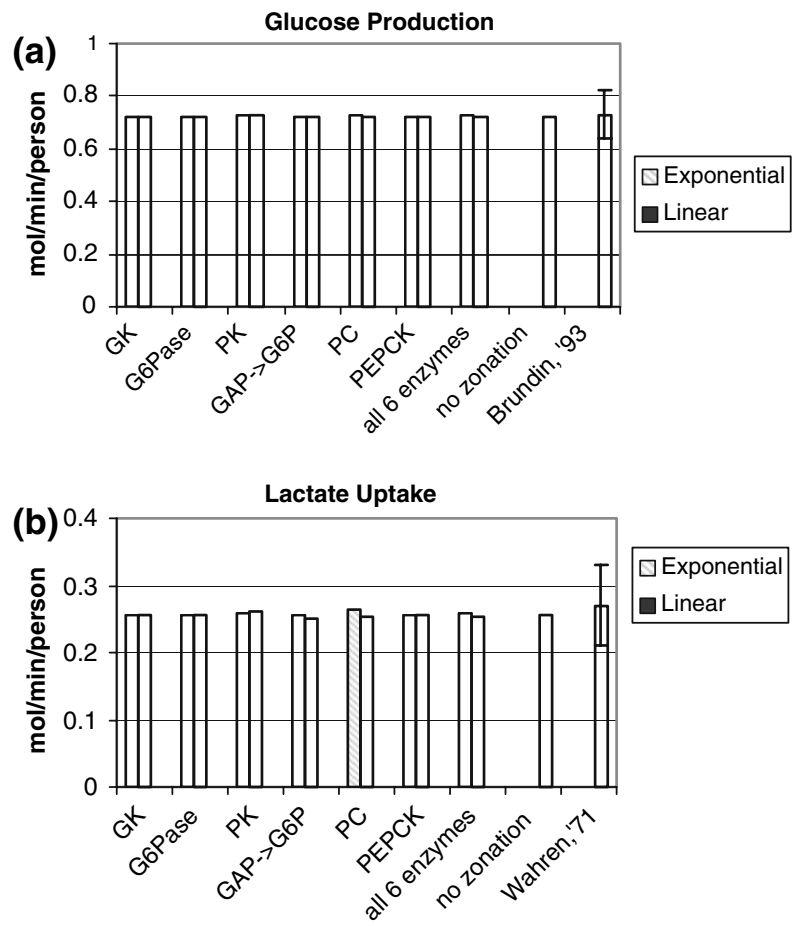

FIGURE 6. (a) Net glucose production by the liver and (b) net lactate uptake by the liver at the fasted, resting state, using blood flow $=1.47 \mathrm{l} / \mathrm{min}$ and parameters given in Tables 1 and 2. Results are shown for both exponential and linear zonation functions. Results were calculated using a single enzyme with a zonation function, then with zonation in all six enzymes simultaneously, and also with no zonation (i.e. constant $V_{\text {max }}$ 's). Experimental data from the literature are shown for comparison.

actually calculated from measurements of maximal enzyme activities and substrate concentrations from the tissue extracts, and assuming Michaelis-Menten kinetics, so there is significant room for error there. Secondly, the cultured hepatocyte system is, at best, an approximation of the two regions of the liver parenchyma in vivo.

The fluxes through each of these six reactions (calculated with zonation in all six reactions, compared to no zonation) are shown in Fig. 8, after normalization to the flux at $x / L=0$. Again, fluxes in each reaction 
(a) No zonation
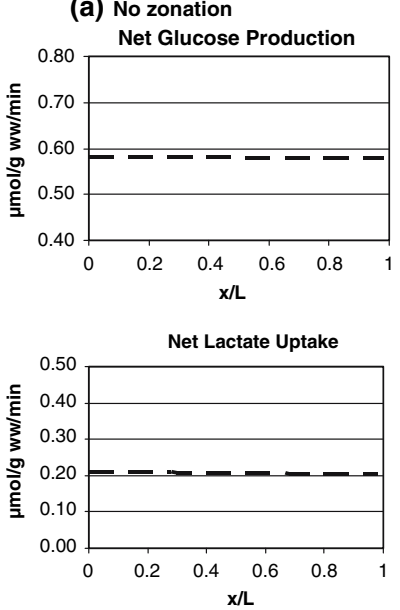

(e) GAP-> G6P
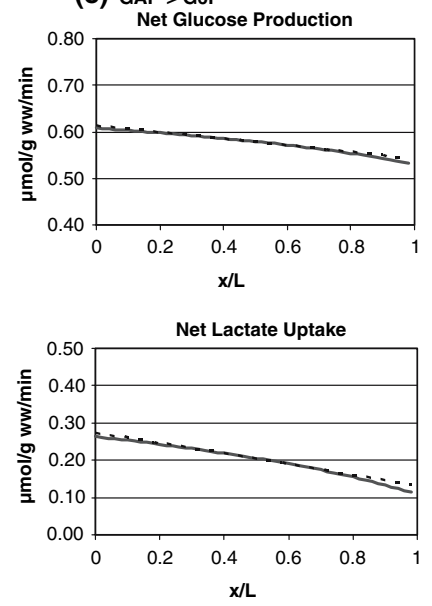

(b) GK

Net Glucose Production

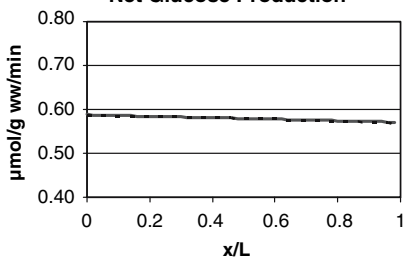

$\mathbf{x} / \mathbf{L}$

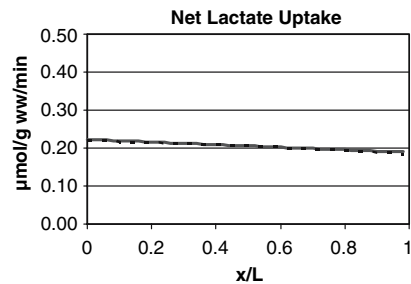

(f) PEPCK

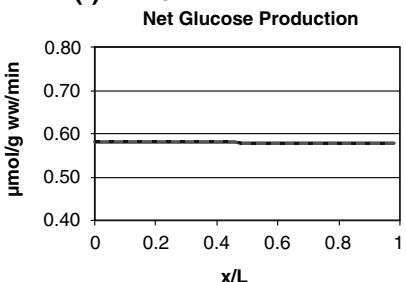

$\mathbf{x} / \mathbf{L}$

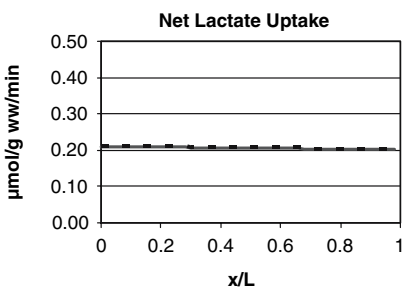

(c) PK
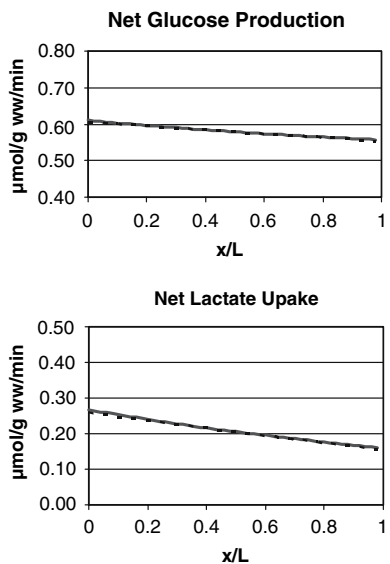

(g) PC

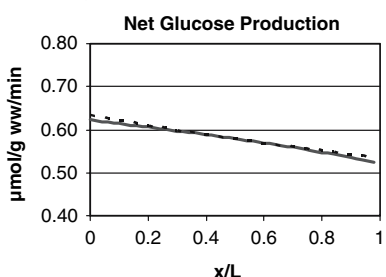

$\mathrm{x} / \mathrm{L}$

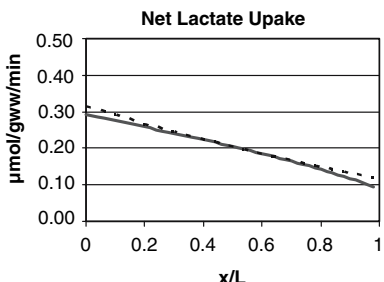

(d) G6Pase

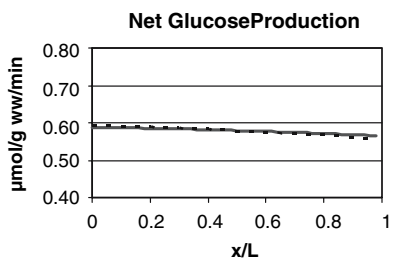

Net Lactate Uptake

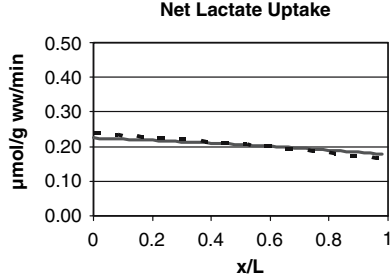

(h) All Six Enzymes

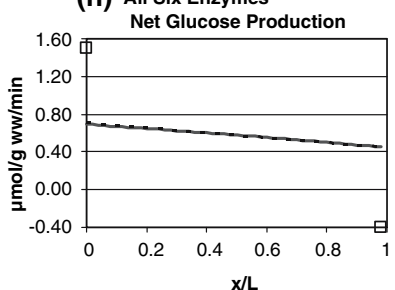

$\mathrm{x} / \mathrm{L}$

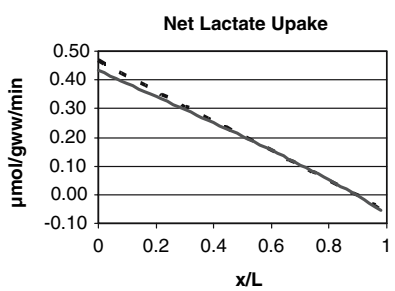

— linear zonation ... exponential zonation $\square$ liver tissue $\circ$ hepatocytes

FIGURE 7. Net rates of glucose production, $\mathbf{J}_{\mathrm{GLC}, t \rightarrow b, \text {,net }}$ and lactate uptake $\mathbf{J}_{\mathrm{LAC}, \mathrm{b} \rightarrow \mathrm{t}, \mathrm{net}}$ by the tissue along the length of the sinusoid, in fasted, resting condition. (a) no zonation; (b)-(g) with zonation only for the enzyme indicated in the graph title, with all other enzymes having constant activity; solid line: linear zonation; dotted line: exponential zonation; (h) zonation of all six enzymes simultaneously, compared with experimental data from Jungermann; ${ }^{37}$ solid line: linear zonation function; dotted line: exponential zonation function; $\square$ : tissue extracts from periportal (shown at $x / L=0)$ and perivenous $($ shown at $x / L=1$ ) zones of microdissected rat liver parenchyma, with fluxes calculated from measured local enzyme activities and substrate concentrations and assuming Michaelis-Menten kinetics; 0 : measured in cultured hepatocytes that have been stimulated to resemble either periportal (shown at $x / L=0$ ) or perivenous (shown at $x / L=1$ ) cells, and placed in media representing the fasted state.

are nearly constant along the length when there is no zonation, indicating that there is little effect of potential concentration gradients on flux distributions. The axial variations become much more significant with the incorporation of enzyme zonation, with the glycolytic fluxes (GK, PK) increasing with distance and the gluconeogenic fluxes (G6Pase, F1,6BPase, PEPCK, PC) decreasing. For example, the calculated glucokinase flux, with zonation, increases 6-fold between periportal $(x / L=0)$ and perivenous $(x / L=1)$. This result is identical to the 6-fold increase in glycolytic flux measured in periportal-like vs. perivenous-like hepatocytes. ${ }^{38}$ On the other hand, the calculated G6Pase flux decreases between periportal and perivenous, but to a much lesser extent than that reported by Jungerman (5\% decrease in calculated value, compared to $48 \%$ decrease in measured gluconeogenic flux). The G6Pase reaction flux does not change as significantly as the maximal activity for G6Pase (Fig. 5), since the flux is tempered by the substrate concentration and the relatively large blood flow rate in the liver.

The parameter sensitivities were calculated using the model without zonation representing the fasted, resting state. The sensitivities of overall glucose production $\left(P_{\mathrm{GLC}}\right)$ and lactate uptake $\left(P_{\mathrm{LAC}}\right)$ relative to the kinetic parameters are shown in Fig. 9. The lactate uptake is 


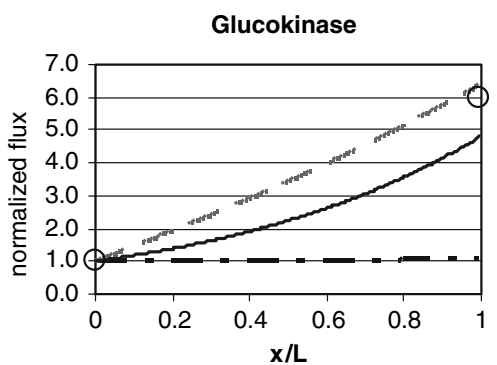

GAP-->G6P

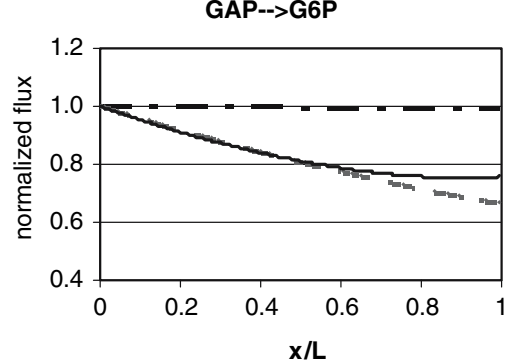

$\mathbf{x} / \mathrm{L}$

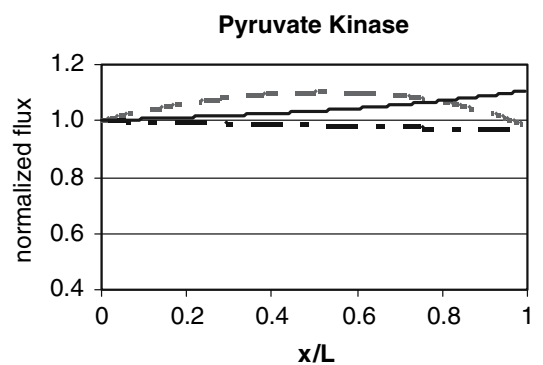

PEPCK

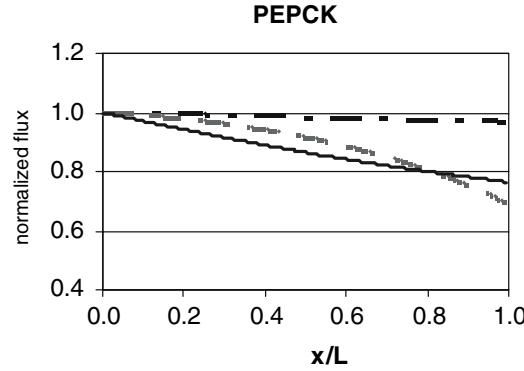

$\mathbf{x} / \mathbf{L}$
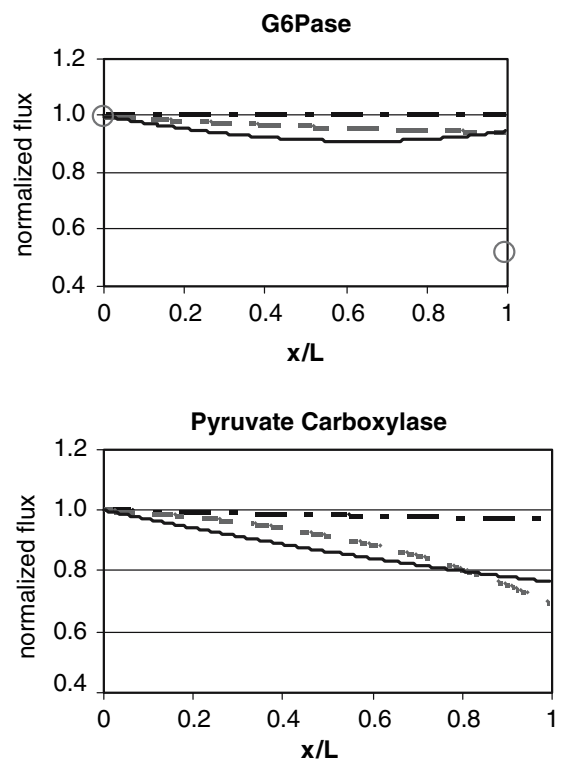

exponential zonation

FIGURE 8. Reaction fluxes as a function of sinusoid length, during the fasted, resting state, with zonation of all six reactions, and without zonation. Fluxes are normalized to the flux value at $x / L=0$. Lines represent simulations, open circles represent experimental data from cultured hepatocytes, stimulated to resemble either periportal $($ shown at $x / L=0)$ or perivenous $($ shown at $x / L=1)$ cells, and placed in media representing the fasted state, from Jungerman, 1983.

much more sensitive to parameters than the glucose output, since the glucose output is a function of both glycogen degradation (which is set to a constant) as well as the lactate uptake and intermediary reactions. Not surprisingly, the fluxes are most sensitive to parameters in some of the key regulatory reactions, such as PK, PC, and F1,6BPase (represented by $\mathrm{GAP} \rightarrow \mathrm{G} 6 \mathrm{P}$ ). Also note that the sensitivity to the parameters related to nonspecific ATP demand is also relatively high. But for all parameters, the sensitivities of overall glucose output and lactate uptake are less than one, indicating that the results are stable and that no single parameter has an amplification effect on the overall fluxes.

The sensitivities for all internal fluxes and species concentrations are shown in Tables A.1 and A.2. In general, concentrations and fluxes were more sensitive to $V_{\max }$ 's than to $K_{\mathrm{m}}$ 's, indicating the importance of having good estimates especially for the $V_{\max }$ 's. The $V_{\max }$ 's corresponding to gluconeogenic reactions were most influential, i.e. G6Pase, PC, GAP $\rightarrow$ G6P, and PK (which affects the amount of cycling during gluconeogenesis).

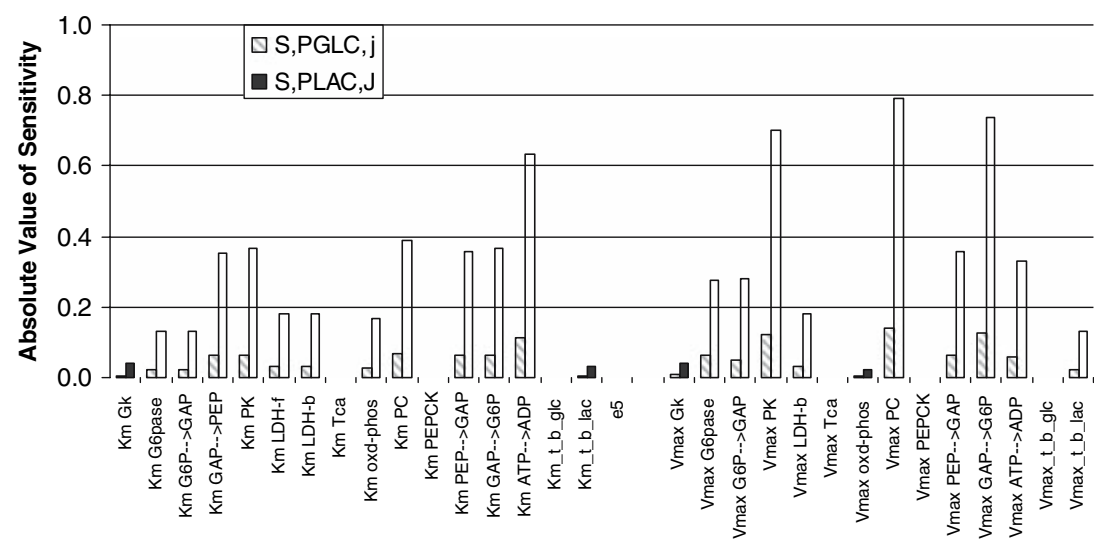

FIGURE 9. Absolute values of the sensitivities of net overall glucose production $\left(S_{P G L C, j}\right)$ and lactate uptake $\left(S_{P L A C, j}\right)$ to kinetic parameters $j$, given in the $x$-axis. 
The most influential $K_{\mathrm{m}}$ is $K_{\mathrm{m}, \mathrm{ATP} \text { ADP, }}$ which appears in the nonspecific ATP usage kinetic expression. This parameter does not have direct physiological significance, and thus an experimental value is unavailable. The transport parameters had relatively little effect on the results, indicating that the system is more metabolically driven rather than transport driven.

The sensitivities of all the fluxes to all the parameters are all less than one, indicating that there were no cases of disproportionate effects of parameters on flux distributions. On the other hand, the OXA concentration was hypersensitive to $V_{\text {max,PEPCK }}, V_{\text {max,PC, }}$ $V_{\text {max,ATP_ADP, }}$ and to a less extent, $V_{\text {max,OxPhos. This }}$ results from the low in vivo concentration of OXA $(0.0003 \mu \mathrm{mol} / \mathrm{g} / \mathrm{ww})$.

The model, without zonation, was modified to account for physiological changes during high-inten- sity exercise $(0.195 \mathrm{~kW})$, and the overall calculated glucose output and lactate uptake rates were compared to experimental values. Figure 10 contains simulation results representing the resting state and quasi-steady state at $20 \mathrm{~min}$ of exercise. During longer periods of exercise many other physiological changes occur which are not represented in the model. It is known that blood flow through the liver decreases by about $50 \%{ }^{69}$ during high intensity exercise as nutrients and oxygen are diverted to the heart and muscle tissue. The results in Fig. 10(ii) indicate that a $50 \%$ decrease in blood flow rate alone has negligible effect on glucose production and lactate uptake, and thus is not sufficient modification of the model to represent exercise. According to Wahren, ${ }^{69}$ arterial lactate concentration increases 5-fold in humans during exercise, and assuming negligible

(a) Net Glucose Production

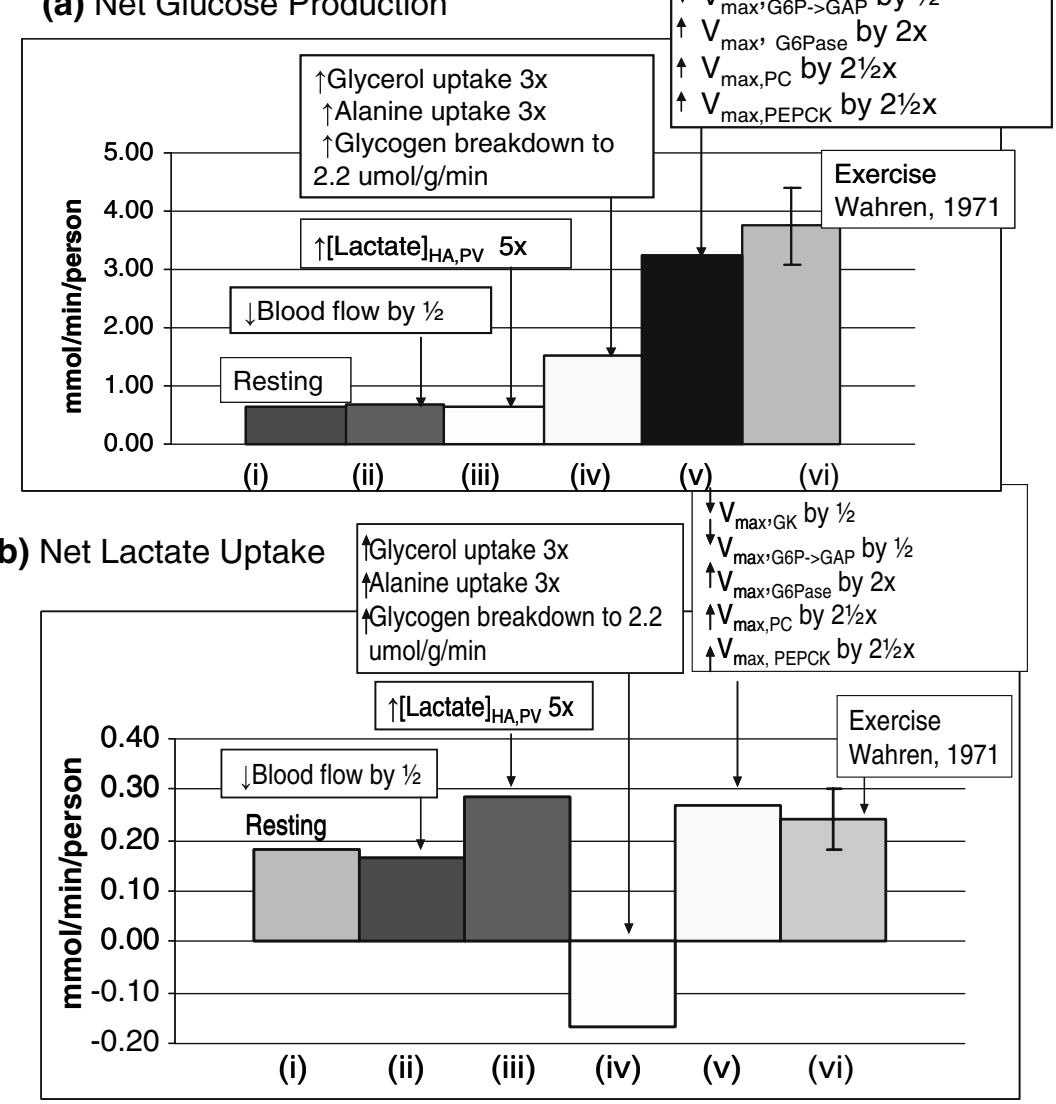

FIGURE 10. Net glucose production and lactate uptake by the liver, calculated at quasi-steady state at 20 min following transition from resting to high-intensity exercise. i) Resting, overnight fasted state (i.e. initial condition); ii) liver blood flow rate decreased by $\frac{1}{2}$; iii) same parameters as in (ii), plus: 5 -fold increase in lactate concentration in the combined hepatic artery/portal vein input to the liver ( $C_{\text {LAC,blood }}^{\infty}$ to $6.0 \mathrm{mM}$; iv) same parameters as in (iii), plus: 3 -fold increase in glycerol uptake, to $0.51 \mathrm{umol} / \mathrm{g} / \mathrm{min}$, increase in glycogen breakdown to $2.2 \mathrm{umol} / \mathrm{g} / \mathrm{min}$, and 3-fold increase in alanine uptake; $v$ ) same changes as in (iv), plus: changes in $V_{\text {max }}$ of GK, G6Pase, PFK, PC, and PEPCK resulting from the decrease in insulin concentration and increase in glucagon during exercise; vi) measured value at high intensity exercise. ${ }^{69}$ 
lactate uptake in the gut, the value for $C^{\infty}$ LAC,blood was increased 5-fold to $6.0 \mathrm{mM}$. Figure 10(iii) shows that this increase in lactate concentration also has negligible effect on glucose output, although lactate uptake does increase by 30\%. Glycerol uptake rate was then increased 3-fold and the glycogen degradation rate was increased to $2.2 \mathrm{umol} / \mathrm{g} / \mathrm{min}$, based on measurements in humans by, ${ }^{69}$ and amino acid uptake (represented by alanine uptake) was increased 3fold. $^{71}$ These fluxes are assumed to be constant over the 20-min simulation period. The incorporation of these changes into the model causes a doubling of hepatic glucose production (Fig. 10iv), but the changes are still not enough to account for the 5-fold increase in observed glucose output during exercise. ${ }^{69}$ Lactate uptake actually becomes negative, which is an unrealistic resulting indicating that there is a bottleneck in the gluconeogenic reactions that keeps the extra substrate from exiting the tissue as glucose.

It is known that exercise causes a $28 \%$ decrease in arterial insulin concentration, ${ }^{69,70}$ which is already low because of the fasting state; more specifically, a $37 \%$ decrease occurs at high intensity exercise. ${ }^{69}$ Exercise also causes an increase in glucagon concentration, ${ }^{70,32}$ ). Additionally, the increased adrenergic activity during exercise causes an increase in adrenaline, noradrenaline, ${ }^{17}$ and epinephrine. ${ }^{32}$ The insulin decrease and glucagon increase, together, cause the maximal enzyme activity of PK to decrease ${ }^{35}$, and of G6Pase, ${ }^{3}$ PEPCK and F1,6 bisphosphatase to increase ${ }^{35}$. Glucagon induces the inhibition of PFK and $\mathrm{PK}$ via short-term allosteric action ${ }^{35}$, while insulin acts conversely. Glucagon also induces PEPCK and F1,6bisphosphatase activity over the long-term via gene expression, with inverse action by insulin. Simulations by El-Refai and Bergman (1976) have also suggested that the maximal activity of GK increases $100 \%$ upon insulin stimulation.

The hormonal changes during exercise described in the previous paragraph were incorporated into the model by decreasing $V_{\max , \mathrm{GK}}$ and $\mathrm{V}_{\max , \mathrm{G} 6 \mathrm{P} \rightarrow \mathrm{GAP}}$ by $50 \%$, increasing $V_{\max , G 6 \text { Pase }} 2$-fold, and increasing $V_{\text {max,PC }}$ and $V_{\text {max,PEPCK }} 2 \frac{1}{2}$-fold immediately upon switching to the high-exercise state. As shown in Fig. 10(v), these changes cause a 4-fold increase in hepatic glucose production, which compares favorably with experimental values (Fig. 10vi). Calculated lactate uptake also increases, matching the experimental value.

\section{DISCUSSION}

A model of reaction and transport in the liver was developed that can describe the metabolite concen- tration and reaction flux dynamics separately within the tissue and blood domains. The blood domain contains equations for convection, axial dispersion, and transport to the surrounding tissue; and the tissue domain consists of reactions representing key processes of glycolysis, gluconeogenesis, glycogenolysis, tricarboxylic acid cycle, oxidative phosphorylation, and fatty acid degradation and synthesis. The model includes the metabolic heterogeneity of the liver by incorporating spatial variation of key enzymatic maximal activities.

This model builds upon and integrates information from previous models of liver metabolism that have focused on either subsets of reactions, have included comprehensive set of metabolic pathways assuming well-mixed tissue, or have described the heterogenous nature of the liver in terms of a single species or reaction. Furthermore, the kinetic parameters and the data used for validation were based for the most part on human data, and to a lesser extent, on in vivo experiments with dogs or in vitro experiments with rats. We believe that this emphasis on use of in vivo data to obtain kinetic parameters circumvents the common criticism of complex models that use kinetic parameters that have been measured in environments that are very different from the intact system. Given that, there is still considerable uncertainty in parameter values, and assumptions made about $K_{\mathrm{m}}$ values then affected the values of $V_{\max }$ 's needed to be consistent with the in vivo data. Fortunately, our sensitivity analysis showed that the results were much less sensitive to the selection of $K_{\mathrm{m}}$ 's than to $V_{\max }$ 's, and the $V_{\max }$ 's that were most influential belong to the regulatory reactions in glycolysis and gluconeogenesis, for which there is substantial availability of in vitro experimental data. The kinetic parameters of the ATPase reaction also were among the most influential. Since this reaction represents many ATP-using reactions and the parameters have no direct physiological meaning, it may be better to consider this reaction flux as an adjustable parameter that has upper and lower limits derived from in vivo flux balance analysis.

Simulation results at the overnight fasted, resting state agree closely with experimental values of fluxes and concentrations, and overall glucose uptake and lactate output are confirmed with independent data. The incorporation of zonation of glycolytic and gluconeogenic enzyme activities causes the expected increase in glycolysis and decrease in gluconeogenesis along the sinusoid length. The results from simulations with and without zonation indicate that transport gradients are not sufficient to account for observed axial variations in gluconeogenesis and glycolysis, and that a distributed-in-space arrangement 
of enzyme activities is necessary to achieve this result. By incorporating the zonation of each enzyme separately in the model, we could ascertain the importance of each enzyme to the axial variation in glucose and lactate fluxes. While several enzymes were more influential, e.g. PK, F1,6BPase (represented by $\mathrm{R}_{\mathrm{GAP} \rightarrow \mathrm{G} 6 \mathrm{P}}$ ), and $\mathrm{PC}$, no single enzyme alone with zonation caused a significant axial variation in fluxes. The zonation of all reactions combined served to increase the axial variations of glucose and lactate fluxes.

The physical causes of zonation, whether resulting from hormonal or oxygen gradients or differential innervation, as have been hypothesized ${ }^{38}$ have not been addressed in this work. While substantial evidence exists that enzymes of the fatty acid metabolic pathways also exhibit distributed activities, ${ }^{40,6}$ the analysis of enzymatic zonation presented here is strictly limited to the central carbohydrate pathways.

The model results are based on the assumption that the sinusoids are structured in parallel, and have uniform size and velocity. In reality, there is significant variation in both length and blood velocity, with a fraction of the sinusoids switching between having flow and no flow at any one time ${ }^{51}$. Moreover, there is branching in some of the sinusoids, and some of the hepatic arterioles and portal venules may connect with the sinusoid at up to a third of the distance down the sinusoid. The effects of this complicated flow pattern and structure on the simulated metabolic results presented here are non-obvious, and will be the subject of a future study.

During high-intensity exercise, the hepatic glucose production in humans increases nearly 5 -fold, with a smaller increase in lactate uptake. The simulations shown here indicate that observed changes in arterial substrate concentrations and hepatic blood flow rate are not sufficient to shift the liver metabolism enough to account for this increased glucose output. Changes in gluconeogenic and glycolytic enzyme activities, whether caused by exercise-induced changes in insulin, glucagon, adrenaline, noradrenaline, or epinephrine, or even by direct adrenergic stimulation of the liver are needed to achieve the overall metabolic changes observed. The amounts of induction or inhibition of enzymatic activities that were incorporated into the model were based on extrapolation from information from the literature. The simulations have shown that hormonal effects on all the reactions analyzed are crucial for the physiologically realistic response of the liver to exercise, and changes in individual enzyme activities (data not shown) were not sufficient to achieve this.

The changes in hormone concentrations, and the subsequent changes in enzyme activities, do not occur immediately at the onset of exercise. Since these changes in enzyme activities were incorporated in the model at the onset of exercise, the simulated transients are unrealistically fast (not shown), and thus only the steady state simulation results representing the physiological conditions expected at about $20 \mathrm{~min}$ of exercise were presented here. Several modifications to the model are needed to generate more realistic dynamics. Mass balance equations of hormones, especially insulin and glucagon, with upstream arterial concentrations that vary with time according to available experimental data, need to be added to the system. The influence of hormones will be especially visible in the distributed model, since hormone degradation occurs within the liver and significant gradients in hormone concentrations occur along the sinusoid length ${ }^{39}$. The allosteric effects on enzyme activity by the relevant local hormone concentrations (most likely the glucagon/insulin ratio), mediated by cAMP and phosphorylation or dephosphorylation reactions, need to be accounted for in the appropriate kinetic expressions. These changes can be expected to result in a more gradual response to the onset of exercise as well as to changes in dietary conditions.

Simulations were performed based on the fasted state, which is the condition under which many of the human exercise studies are performed. Since relatively simple kinetic expressions were used in the model, the response to exercise in the fed state will not closely match experimental data. Incorporation of allosteric regulatory mechanisms into the key reactions in glycolysis and gluconeogenesis will result in a more robust model that is valid under a variety of nutritional states.

\section{ACKNOWLEDGMENTS}

The helpful suggestions from David Wasserman and Andreas Schwab are gratefully acknowledged. This work was supported by NIH grant (P50GM066309) from the National Institute of General Medical Sciences through the Center for Modeling Integrated Metabolic Systems. A copy of the Fortran code is available from the corresponding author upon request. 
$8888888884888808888888108 \%$

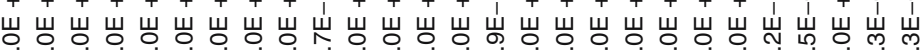

\& 13898 t

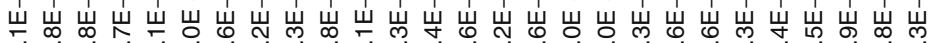
广

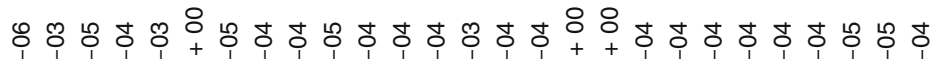

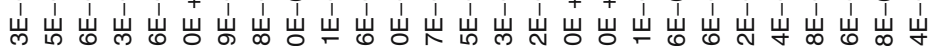

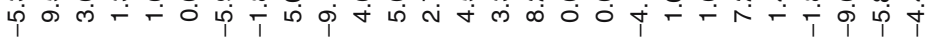

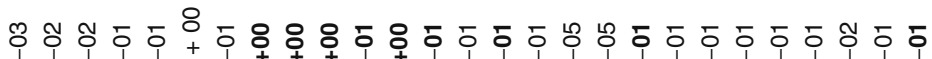

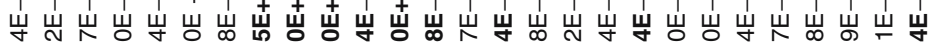

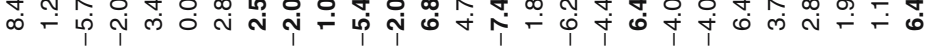

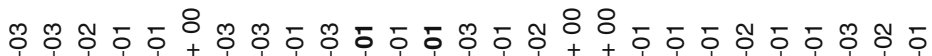

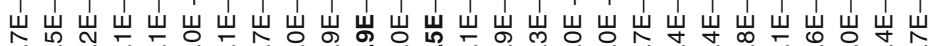
广

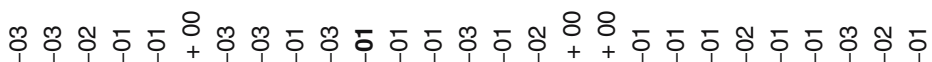

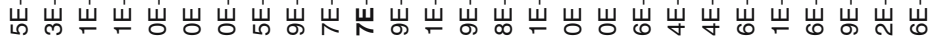
宁 8.8 빙 O O O O ஜ ๊ ₹

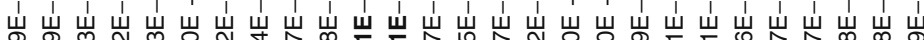
广 ஜ ஜ

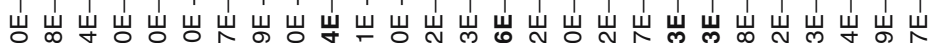

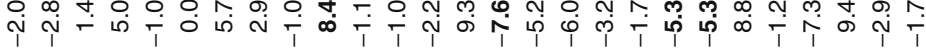

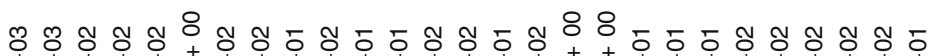

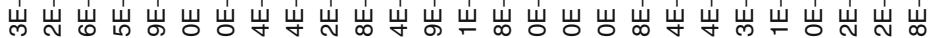
స్

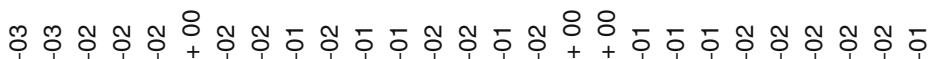

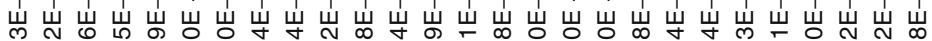

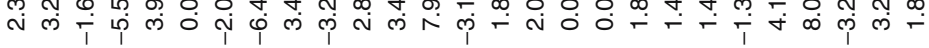

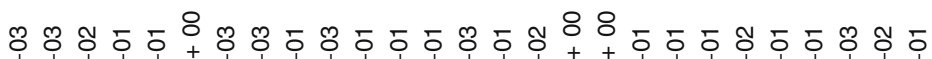

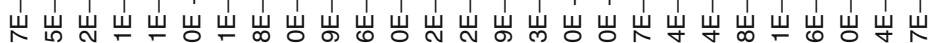
于ं

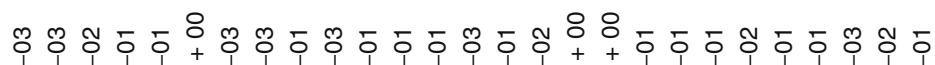

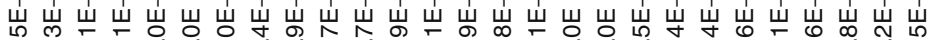
+ ஜ ๊ 嵌 -

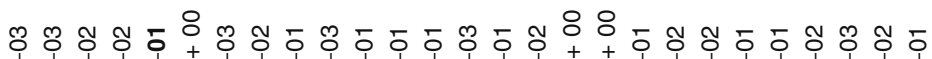

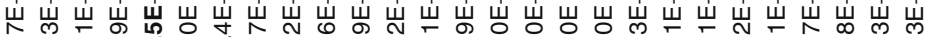
广

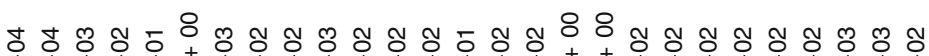

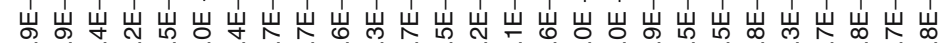

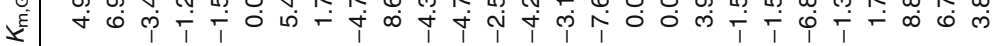

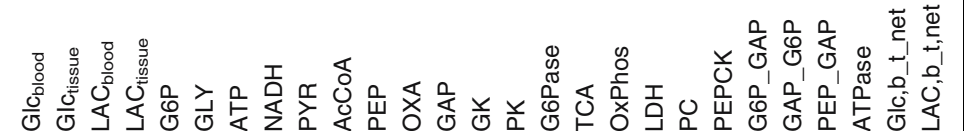




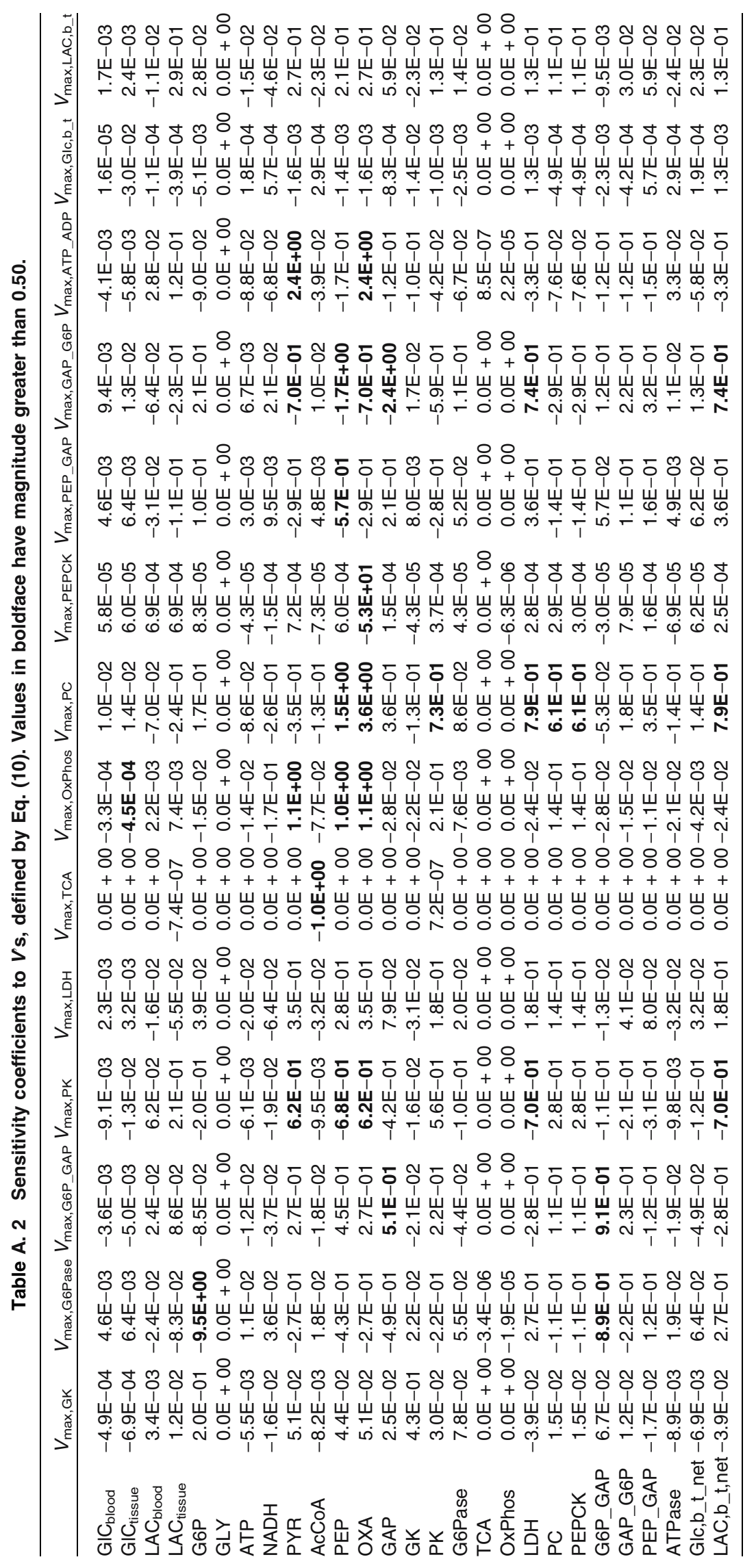




\section{REFERENCES}

${ }^{1}$ Alberty, R. A. Thermodynamics of Biochemical Reactions. Wiley, Hoboken, NJ.

${ }^{2}$ Aubert, A. Modelling of the coupling between brain electrical activity and metabolism. Acta Biotheor. 49:301326, 2001.

${ }^{3}$ Barzilai, N. and L. Rossetti. Role of glucokinase and glucose-6-phosphatase in the acute and chronic regulation of hepatic glucose fluxes by insulin. J. Biol. Chem. 268:25019-25025, 1993.

${ }^{4}$ Bassingthwaite J. B., T. J. Knopp, and J. B. Hazelrig. A concurrent model of capillary tissue exchange. In: Capillary Permeability. New York: Academic press, 1970.

${ }^{5}$ Beard, D. A. and H. Qian. Thermodynamic-based computational profiling of cellular regulatory control in hepatocyte metabolism. Am. J. Physiol. 287(10):26.

${ }^{6}$ Bederman, I. R., T. Kasumov, A. E. Reszko, F. David, H. Brunengraber, and J. K. Kelleher. In vitro modeling of fatty acid synthesis under conditions simulating the zonation of lipogenic $\left[{ }^{13} \mathrm{C}\right]$ acetyl-CoA enrichment in the liver. J. Biol. Chem. 279(41):43217-43226, 2004.

${ }^{7}$ Bergman, R. N. and M. E. Refai. Dynamic control of hepatic glucose metabolism: studies by experiment and computer simulation. Biomed. Eng. 3:411-432, 1975.

${ }^{8}$ Bergmeyer, H. U. Methods of Enzymatic Analysis. Academic press, New York 2265-2290, 1974.

${ }^{9}$ Bjorkman, O., L. S. Eriksson, B. Nyberg, and J. Wahren. Gut exchange of glucose and lactate in basal state and after oral glucose ingestion in postoperative patients. Diabetes 39:747-751, 1990.

${ }^{10}$ Bode, J. C., O. Zelder, H. J. Rumpelt, and U. Wittkamp. Depletion of liver adenosine phospahtes and metabolic effects of intravenous infusion of fructose or sorbitol in man and in the rat. Eur. J. Clin. Invest. 3:436-441, 1973.

${ }^{11}$ Boesiger, P., R. Buchli, D. Meier, B. Steimann, and R. Gitzelmann. Changes of liver metabolite concentrations in adults with disorders of fructose metabolism after intravenous fructose by 31P MRS. Pediatr. Res. 36:436-440, 1994.

${ }^{12}$ Brundin, T. and J. Wahren. Influence of a mixed meal on splanchnic and interscapular energy expenditure in humans. Am. J. Physiol.-Endocrinol. Metab. 260:232-237, 1991.

${ }^{13}$ Brundin, T. and J. Wahren. Whole body and splanchnic oxygen consumption and blood flow after oral ingestion of fructose or glucose. Am. J. Physiol. 264:504-513, 1993.

${ }^{14}$ Chiandussi, L., G. Greco, G. Sardi, A. Vaccarino, C. M. Ferraris, and B. Curti. Estimation of hepatic arterial and portal venous blood flow by direct catheterization of the vena porta through the umbilical cord in man. Preliminary results. Acta Hepato-splenol 15:166.

${ }^{15}$ Deussen, A. and J. B. Bassingthwaighte. Modeling [15O] oxygen tracer data for estimating oxygen consumption. Am. J. Physiol. Heart Circ. Physiol. 270:H1115-H1130, 1996.

${ }^{16}$ Diem, K. and Lentner, C. eds. Documenta Geigy Scientific Tables 7th Edition, Geigy, Basel, 1970, pp. 585.

${ }^{17}$ Enevoldsen, L. H, L. Simonsen, I. A. Macdonald, and J. Bulow. The combined effects of exercise and food intake on adipose tissue and planchnic metabolism. J. Physiol. 561(3):871-872, 2004.

${ }^{18}$ Fogler, S. Elements of Chemical Reaction Engineering (3rd ed.). Prentice Hall, New Jersey 880-881, 2001.
${ }^{19}$ Fournier, R. L. Basic Transport Phenomena in Biomedical Engineering. Taylor and Francis, New York 27-48, 1998.

${ }^{20}$ Galassetti, P., R. H. Coker, D. B. Lacy, A. D. Cherrington, and D. H. Wasserman. Prior exercise increases net hepatic glucose uptake during a glucose load. Am. J. Physiol. 276:E1022-E1029, 1999.

${ }^{21}$ Gannon, M. C., N. Ercan-Fang, V. L. Ratth, J. L. Treadway, M. R. Taylor, and F. Q. Nuttall. Integrated effects of multiple modulators on human liver glycogen phosphorylase a. Am. J. Physiol.-Endocrinol. Metab. 283:29-37, 2002.

${ }^{22}$ Garfinkel, D. Simulation of the Krebs cycle and closely related metabolism in perfused rat liver. I. Construction of the model. Comput. Biomed. Res. 4:1-17, 1971.

${ }^{23}$ Garfinkel, D. Simulation of the Krebs cycle and closely related metabolism in perfused rat liver. II. Properties of the model. Comput. Biomed. Res. 4:18-42, 1971.

${ }^{24}$ Goresky, C. A. Uptake in the liver: the nature of the process. Int. Rev. Physiol. 21:65-79, 1980.

${ }^{25}$ Goresky, C. A. and B. E. Nadeau. Uptake of materials by the intact liver, the exchange of glucose across the cell membrane. J. Clin. Invest. 53:634-646, 1974.

${ }^{26}$ Goresky, C. A., G. G. Bach, and B. E. Nadeau. Uptake of materials by the intact liver. The transport and net removal of galactose. J. Clin. Invest. 52:991-1009, 1973.

${ }^{27}$ Gray, M. R. and Y. K. Tam. The series-compartment model for hepatic elimination. Drug Metab. Dispos. 15:2731, 1986.

${ }^{28}$ Gross, R. C., E. H. Eigenbrodt, and J. W. Farguhar. Endogenous triglyceride turnover in liver and plasma of the dog. J. Lipid Res. 8:114-125, 1967.

${ }^{29}$ Guder, W. G. and U. Schmidt. Liver cell heterogeneity: The distribution of pyruvate kinse and phosphoenolpyruvate carboxykinase (GTP) in the liver lobule of fed and starved rats. Hoppe-Seyler's Z. Physiol. Chem. 357:S17931800, 1976.

${ }^{30}$ Gyorgy, B., Z.-J. Yang, M. Meguid, A. Laviano, and N. Szeverenyi. Effects of fasting, intermittent feeding, or continous parenteral nutrition on rat liver and brain energy metabolism as assessed by 31P-NMR. Physiol. Behav. 58:521-527, 1995.

${ }^{31}$ Hiroshi, M., G. Shulman, E. J. Peters, M. H. Wolfe, D. Elahi, and R. R. Wolfe. Hormonal control of substrate cycling in humans. J. Clin. Invest. 81:1545-1555, 1988.

${ }^{32}$ Howlett, K., D. Angus, J. Proietto, and M. Hargeaves. Effect of increased blood glucose availability on glucose kinetics during exercise. J. Appl. Physiol. 84:1413-1417, 1998.

${ }^{33}$ http://arbl.cvmbs.colostate.edu/hbooks/pathphys/digestion/liver/histo_hcytes.html.

${ }^{34}$ Hultman, E., L. H. Nilson, and K. Sahlin. Adenine nucleotide content of human liver. Scand. J. Clin. Invest. 35:245-251, 1975.

${ }^{35}$ Ito, J., T. Kuzumaki, K. Otsu, Y. Iuchi, and K. Ishikawa. Hormonal regulation of aldolase $\mathrm{B}$ gene expression in rat primary cultured hepatocytes. Arch. Biochem. Biophy. 350:291-297, 1998.

${ }^{36}$ Jensen, M. D. Gender differences in regional fatty acid metabolism before and after meal ingestion. J. Clin. Invest. 96:2297-2303, 1995.

${ }^{37}$ Jensen, M. D. Regional glycerol and free fatty acid metabolism before and after injestion. Am. J. Phsiol. 276:E863-E869, 1999. 
${ }^{38}$ Jungermann, K. Functional significance of hepatocyte heterogeneity for glycolysis and gluconeogenesis. Pharmacol. Biochem. Behav. 18(Suppl. 1):409-414, 1983.

${ }^{39}$ Jungermann, K. Metabolic zonation of liver parenchyma: significance for the regulation of glycogen metabolism, gluconeogenesis and glycolysis. Diabetes Metab. Rev. 3(1):269-293, 1987

${ }^{40}$ Jungermann, K. Metabolic zonation of liver parenchyma. Semin. Liver Dis. 8(4):329-341, 1988.

${ }^{41}$ Jungermann, K. Role of intralobular compartmentation in hepatic metabolism. Diabete \& Metabolisme (Paris). 18:81-86, 1992.

${ }^{42}$ Jungermann, K., R. Heilbronn, N. Katz, and D. Sasse. The glucose/glucose-6-phosphate cycle in the periportal and perivenous zone of rat liver. Eur. J. Biochem. 123:429-436, 1982.

${ }^{43}$ Jungermann, K., H. F. Teutsch, N. Katz, and D. Sasse. Heteregeneous reciprocal localization of fructose 1, 6 bisphosphatase and of glucokinase in micro dissected periportal and perivenous rat liver tissue. FEBS Lett. 83:272276, 1977.

${ }^{44}$ Jones, J. G., M. A. Solomon, S. M. Cole, A. D. Sherry, and C. R. Malloy. An integrated (2)H and (13)C NMR study of gluconeogenesis and TCA cycle flux in humans. Am. J. Physiol. Endocrinol. Metab. 281(4):E848-856, 2001.

${ }^{45}$ Katz, N., H. R. Teutsch, D. Sassee, and K. Jungermann. Heterogeneous distribution of glucose-6-phosphatase in microdissected periportal and perivenous rat liver tissue. FEBS Lett. 72(2):226-230, 1977.

${ }^{46}$ King, R. B., G. M. Raymond, and J. B. Bassingthwaighte. Modeling blood flow heterogeneity. Ann. Biomed. Eng. 24:352-372, 1996.

${ }^{47}$ Koo, A. and I. Y. Liang. Microvascular filling pattern in rat liver sinusoids during vagal stimulation. J. Physiol. 295:191-199, 1979.

${ }^{48} \mathrm{Krebs}, \mathrm{H}$. A. The redox state of nicotinamide adenine dinucleotide in the cytoplasm and mitochondria of rat liver. Adv. Enzyme Regul. 5:409-434, 1967.

${ }^{49}$ Kreft, A. and A. Zuber. On the physical meaning of the dispersion equation and its solutions for different initial and boundary conditions. Chem. Eng. Sci. 33:1471-1480, 1978.

${ }^{50}$ LeCouteur, D. Liver research team, Concorde RG hospital, University of Sydney, Sydney, Australia. http:// www.chmeds.ac.nz/research/liversievefl/background.htm.

${ }^{51}$ MacPhee, P. J., E. E. Schmidt, and A. C. Groom. Intermittence of blood flow in liver sinuoids, studied by highresolution in vivo microscopy. Am. J. Physiol. 269:G692G698, 1995.

${ }^{52}$ Magnusson, I., W. C. Schumann, G. E. Bartsch, V. Chandramouli, K. Kumaran, J. Wahren, and B. R. Landau. Noninvasive tracing of Krebs cycle metabolism in liver. J. Biol. Chem. 266(11):6975-6984, 1991.

${ }^{53}$ Matsumura, T., T. Kashiwagi, H. Meren, and R. G. Thurman. Gluconeogenesis predominates in periportal regions of the liver lobule. Eur. J. Biochem. 144:409-415, 1984.

${ }^{54}$ Morikawa, S., T. Inubushu, K. Takahashi, H. Ishii, and K. Ozawa. Gluconeogenesis and phosphoenergetics in rat liver during endotoxemia. J. Surg. Res. 74:179-186, 1998.
${ }^{55}$ Petersen, K. F, T. Price, G. W. Cline, D. L. Rothman, and G. I. Shulman. Contribution of net hepatic glycogenolysis to glucose production during the early postprandial period. Am. J. Physiol. 270:186-191, 1996.

${ }^{56}$ Rappaport, A. M. Hepatic blood flow: morphologic aspects and physiologic regulation. Int. Rev. Physiol. 21:1-63, 1980.

${ }^{57}$ Reich, J. G. and E. E. Selkov. Energy Metabolism of the Cell: A Theoretical Treatise. Academic Press, London, New York.

${ }^{58}$ Renkin, E. M. Multiple pathways of capillary permeability. Circ. Res. 41:735-743, 1977.

${ }^{59}$ Roberts, M. S. and M. Rowland. Correlation between invitro microsomal enzyme activity and whole organ hepatic elimination kinetics: analysis with a dispersion model. $J$. Pharm. Pharmacol. 38:177-181, 1985.

${ }^{60}$ Rowland, M., A. B. Ahmad, P. N. Bennett, and M. S. Roberts. Models of hepatic drug clearance: discrimination between the 'well stirred' and 'parallel-tube' models. $J$. Pharm. Pharmacol. 35(4):219-224, 1983.

${ }^{61}$ Salem, J., G. Saidel, W. Stanley, and M. Cabrera. Mechanistic model of myocardial energy metabolism under normal and ischemic conditions. Ann. Biomed. Eng. 30:202-216, 2002.

${ }^{62}$ Saville, B. A., M. R. Gray, and Y. K. Tam. Models of hepatic drug elimination. Drug Metab. Rev. 24(1):49-88, 1992.

${ }^{63}$ Shigehiro, M., T. Inubushi, K. Takahashi, H. Ishii, and K. Ozawa. Gluconeogenesis and phosphoenergetics in rat liver during endotoxemia. J. Surg. Res. 74:179-186, 1998.

${ }^{64}$ Shulman, G. I., P. W. Ladenson, M. H. Wolfe, E. C. Ridgway, and R. R. Wolfe. Substrate cycling between gluconeogenesis and glycolysis in euthyroid, hypothyroid, and hyperthyroid man. J. Clin. Invest. 76:757-764, 1985.

${ }^{65}$ Sindelar, D. K, C. A. Chu, P. Venson, E. P. Donahue, D. W. Neal, and A. D. Cherrington. Basal hepatic glucose production is regulated by the portal vein insulin concentration. Diabetes 47:523-529, 1998.

${ }^{66}$ Song, S. D. Department of Biological Sciences, Kyungpook National University, Korea. http://bh.knu.ac.kr/ sdsong/ images/HB16-Liver.gif.

${ }^{67}$ Stubs, M., R. L. Veech, and H. A. Krebs. Control of the redox state of the nicotinamide-adenine dinucleotide couple in rat liver cytoplasm. Biochem. J. 126:59-65, 1972.

${ }^{68}$ Tsuji, A., T. Yoshikawa, K. Nishide, H. Minami, M. Kimura, T. Tersaki, E. Miyamoto, C. Nightingale, and T. Yamana. Physiologically based pharmacokinetic model, Tissue distribution and elimination in rats. J. Pharm. Sci. 72(11):1239-1252, 1983.

${ }^{69}$ Wahren, J., P. Felig, G. Ahlborg, and L. Jorfeldt. Glucose metabolism during leg exercise in man. J. Clin. Invest. 50:2715-2725, 1971 .

${ }^{70}$ Wahren, J., P. Felig, G. Ahlborg, R. Hendler, and L. Hagenfeldt. Substrate turnover during prolonged exercise in man. J. Clin. Invest. 53:1080-1090, 1974.

${ }^{71}$ Wasserman, D. H., R. J. Geer, P. E. Williams, T. Becker, D. Brooks Lacy, and N. N. Abumrad. Interaction of gut and liver in nitrogen metabolism during exercise. Metabolism 40:307-314, 1991. 